\title{
Choice Set Definition Issues in A KuHN-TuCKer Model of RECREATION DEMAND*
}

\author{
By \\ DANIEL J. PHANEUF ${ }^{* *}$ \\ Department of Agricultural and Resource Economics, North Carolina State University, Box 8109, Raleigh, \\ NC 27695-8109 \\ JOSEPH A. HERRIGES \\ Department of Economics, Iowa State University, Ames, IA 50011-1070
}

\begin{abstract}
Much of the literature on choice sets has focused on how alternative specifications of market scope and site definition impact site selection models and the resulting welfare estimates per choice occasion. In this paper, choice set definition issues are investigated using the KuhnTucker model, which integrates the site selection and participation decisions in a unified and utility theoretic framework. This allows us to consider the impact that alternative site set definitions may have on both where individuals recreate and the numbers of trips they take. Using data from the 1997 Iowa Wetlands Survey we examine the effects on estimates and welfare measures of choice sets representing various levels of site aggregation and market scope. We find that significant differences in welfare measures arise from changing choice set definitions.
\end{abstract}

KEY WORDs: Choice Set Definition, Kuhn-Tucker Model

Suggested RunNing Head: Choice Set Definition Issues in Kuhn-Tucker Models

January 4, 2000 


\section{INTRODUCTION}

Choice set definition in recreation demand modeling is a complex issue for which economic theory provides relatively little guidance. Broadly speaking, the issue can be divided into two areas: the determination of the proper scope of the market (i.e., what goods enter into an individual's choice set during the timeframe of interest) and the decision as to how sites are to be defined and/or aggregated. These decisions must be made both on a conceptual level (e.g., considering whether an individual actually knows about all of the available options) and on a practical level, recognizing the limitations in empirical setting of both the available data and the ability of the specified model to handle a large number of alternatives. In determining the scope of the market, for example, attention must be given to both the geographical and horizontal extents of the market. In the case of recreational day-trips, where the price is determined largely by a site's the distance from an individual's home, the geographical scope can often be effectively limited via a feasible cut-off distance. ${ }^{1}$ However, the horizontal extent of the market (i.e., what substitute goods to include in the model) is not so cleanly defined. When modeling the demand for salt water fishing, should one include fresh water alternatives as potential substitutes? When expanding the geographical scope of the market, more potential substitute activities will inevitably fall into the expanded geographical region. Should these be included? Is it sufficient to include expenditures on horizontal substitutes simply as part of a numeraire good, or is important information lost by not including the characteristics/quality levels of these sites in the model?

There is also an information extent of the market to consider. Sites that are physically possible for the individual to visit may not, in fact, enter that individual's decision making process if they are unaware of the sites' characteristics or even existence. Horowitz (1991), for example, considers this problem in the context of job search, arguing that “...the cost of information often precludes an individual from learning about and applying for all available jobs.” (p. 1239) Similar information costs and constraints potentially limit the scope of the market 
for the recreator as well. Finally, the definition of a site itself is a nontrivial task. In some applications, natural boundaries exist (e.g., in the case of small inland lakes), whereas in others (e.g., in the case of a major river system) a continuum of sites exists. Unfortunately, site definitions are driven as often as not by practical limitations in terms of the data or the model being estimated, despite the fact that different decisions on choice set can lead to significant differences in the welfare measures obtained. ${ }^{2}$

Conceptually and practically related to the choice set definition issues is the challenge of modeling corners in recreation demand. Corner solutions are common in this setting because individuals typically visit only a subset of the available sites, setting the demand for the remaining sites to zero. There is growing literature on methods for dealing with corner solutions in recreation demand (see Herriges, Kling and Phaneuf 1999 for a recent review). The prevalence of corner solutions is linked to choice set definition decisions. An increase in the market scope to be analyzed will invariably lead to more corner solutions, as options are added in which not all individuals will partake. Conversely, a high degree of aggregation will decrease the number of corner solutions, as previously individual sites are lumped together, increasing the likelihood of a visit to one of the aggregated sites. At the extreme, choice set definition determines the types of model that can be feasibly estimated, which in turn influences the resulting welfare estimates. Single site or pooled models, which by definition require either a restricted scope or a high level of aggregation, will typically produce results different from models that can be estimated for a larger number of sites, such as Morey, Rowe and Watson's (1993) repeated nested logit models (RUMs) or linked models that combine site selection and participation decisions (See, e.g. Herriges, Kling, and Phaneuf 1999).

Our objective in this paper is to bring recent developments in the literature on corner solutions, and in particular the Kuhn-Tucker (KT) model (e.g., Wales and Woodland 1983 and Phaneuf, Kling and Herriges 2000), to bear on the choice set definition debate. The KT framework is attractive for two reasons. First, much of the literature on choice set definition has 
focused on how alternative specifications impact site selection models and the resulting welfare estimates per choice occasion. For example, Parsons and Needelman (1992), Feather (1994), and Kaoru, Smith and Oiu (1995) consider how site aggregation alters welfare calculations, whereas Peters, Adamowicz and Boxall (1995) and Parsons and Hauber (1998) emphasize the importance of scope specification. ${ }^{3}$ The Kuhn-Tucker model, however, integrates the site selection and participation decisions in a unified and utility theoretic framework. This allows us to consider the impact that alternative site set definitions may have on both where individuals recreate and the numbers of trips they take. Second, because the KT model starts with the familiar direct utility function, well-known results on aggregation in general literature can be brought to bear in terms of both the specification of and testing for alternative aggregation schemes.

The remainder of the paper is organized as follows. Section II provides a brief overview of the KT model. This framework is then used to model the demand for recreational activities in Iowa wetlands. The underlying data set is detailed in section III. Section IV provides the empirical specification and the resulting parameter estimates using different levels of site aggregation and geographical scope. We then examine the effects that various choice set specifications have on the welfare estimates associated with changes in site characteristics and access. Section V provides a discussion and suggestions for future research.

\section{KUHN-TUCKER MODEL}

Wales and Woodland (1983) and Hanemann (1978) independently suggested the KuhnTucker model for estimation of consumer preferences when binding non-negativity constraints are present in the observed data. ${ }^{4}$ The model begins with utility maximization subject to income and non-negativity constraints. The first order conditions, given the potential for nonconsumption of a subset of the goods, take the form of the Kuhn-Tucker conditions. Formally the consumer is assumed to solve the standard utility maximization problem

$$
\max _{\mathbf{x}, z} u(\mathbf{x}, z, \mathbf{q}, \gamma, \mathcal{E}) \text { s.t. } y=z+\mathbf{p}^{\prime} \mathbf{x}, x_{i} \geq 0
$$


where $\mathbf{x}=\left(x_{1}, \ldots, x_{M}\right)^{\prime}$ is a vector of visits to available recreation sites, $\mathbf{p}=\left(p_{1}, \ldots, p_{M}\right)^{\prime}$ is a vector of prices, $y$ denotes income, $z$ is a numeraire good representing spending on all other goods, $\mathbf{q}=\left(q_{1}, \ldots, q_{M}\right)^{\prime}$ is a vector of attributes of the recreation sites, $\varepsilon=\left(\varepsilon_{1}, \ldots, \varepsilon_{M}\right)^{\prime}$ is a vector of unobserved random components, and $\gamma$ is a vector of parameters to be estimated. Assuming the numeraire good is necessary, the Kuhn-Tucker conditions for this problem take the form

$$
u_{j} \leq p_{j} u_{z} ; x_{j} \geq 0 ; x_{j}\left[u_{j}-p_{j} u_{z}\right]=0, j=1, \ldots, M
$$

where $u_{j}$ indicates the partial derivative of utility with respect to $x_{j}$. Given specific assumptions on the structure of the utility function, the first order conditions in (2) can be rewritten as ${ }^{5}$

$$
\varepsilon_{j} \leq g_{j}(\mathbf{x}, y, \mathbf{q}, \gamma) ; \quad x_{j} \geq 0 ; x_{j}\left[\varepsilon_{j}-g_{j}(\mathbf{x}, y, \mathbf{q}, \gamma)\right]=0, \quad j=1, \ldots, M
$$

where $g_{j}(\cdot)$ is a function of observed variables and parameters to be estimated, determined by the choice of functional form for utility.

Assuming the random variables are distributed via the density function $f_{\varepsilon}(\varepsilon)$, the probability of observing an individual's outcome in the data can be constructed from (3). For example, if the first $k$ goods are positively consumed, the probability of this outcome is given by

$$
\int_{-\infty}^{g_{k+1}} \ldots \int_{-\infty}^{g_{M}} f_{\varepsilon}\left(g_{1}, \ldots, g_{k}, \varepsilon_{k+1}, \ldots, \varepsilon_{M}\right) a b s\left|J_{k}\right| d \varepsilon_{k+1}, \ldots, d \varepsilon_{M},
$$

where $J_{k}$ is a Jacobean transformation term. A probability as in (4) can be computed for each individual in the sample, and maximum likelihood used to recover estimates of the parameter vector. Because of the non-negativity constraints, the demand system, and hence the indirect utility function of interest for welfare analysis, is non-differentiable. If there are $M$ recreation sites available, the individual will have $2^{M}$ different combinations of sites that can be visited, including the possibility of not visiting any recreation sites during the season. Let

$$
\Omega \equiv\{\varnothing,\{1\},\{2\}, \ldots,\{M\},\{1,2\}, \ldots,\{1, M\}, \ldots,\{1,2, \ldots M\}\}
$$


denote the collection of all possible demand patterns (i.e., subsets of $I=\{1,2, \ldots, M\}$ ) and $v_{\omega}\left(\mathbf{p}_{\omega}, \mathbf{q}, y, \gamma, \varepsilon\right)$ denote the indirect utility function when the individual is restricted to the commodities indexed by $\omega \in \Omega$ (i.e., $x_{j}=0 \forall j \notin \omega$ ). The individual's unconditional indirect utility function is then given by

$$
v(\mathbf{p}, \mathbf{q}, y, \gamma, \mathcal{\varepsilon})=\max _{\omega \in \Omega}\left\{v_{\omega}\left(\mathbf{p}_{\omega}, \mathbf{q}, y, \gamma, \mathcal{\varepsilon}\right)\right\}
$$

As a side note, the structure of preferences in (6) highlights the conceptual similarities between the RUM and KT models. In each case preferences are characterized up to an unobserved error term. It is assumed consumers make a choice among discrete alternatives. In RUMs, consumers chose which site to visit on a given choice occasion, while in the KT model they chose the visitation pattern $(\omega \in \Omega)$ for the season. The models differ in that the RUM restricts the analysis to a single choice occasion; thus, choices involving multiple sites are not possible and scale (the number of trips to each site) information is not incorporated. The KT model uses additional information, adding the scale dimension and allowing multiple trips to various sites. In this sense, the KT model can be seen as a generalization of the RUM.

\section{THE IOWA WETLANDS DATA}

The data used in this application come from the 1997 Iowa Wetlands Survey conducted at Iowa State University. The purpose of the survey was to gather information on how Iowans use wetlands in the state, as well as their attitudes towards wetland preservation/restoration programs. ${ }^{6}$ The survey included a variety of questions soliciting actual and hypothetical use of wetlands, as well as contingent valuation and behavior questions. Finally, detailed demographic characteristics and information for constructing travel prices were gathered. This study focuses on the visitation data. The behavioral data are augmented by pheasant count data, provided by the Iowa Department of Natural Resources. 
A sample of 6000 Iowa households was drawn from the general population and from state hunting and fishing license holders and sent a mail survey, from which 3131 useable surveys were returned. $^{7}$ As part of the survey, each individual was provided a copy of the map in Figure 1, dividing the state into 15 zones. ${ }^{8}$ Individuals were asked to record the number of trips made to wetlands in each of the zones during 1997. For this application, 2891 respondents are used, of whom roughly two-thirds visited a wetland in the state during 1997.

Given the site visitation data, the next task is to define choice sets for the models to be applied. In part, this specification depends on the goals of the empirical study. We may wish to consider the demand for and policies affecting wetlands in the entire state. Conversely, we may be interested in a particular resource in the state, such as the Des Moines lobe of the Prairie Pothole Region. The Prairie Pothole Region is a large, fairly unique section of North American, encompassing parts of Iowa, Minnesota, the Dakotas, and the Canadian plains provinces. The area is dotted with indentations, in otherwise flat landscapes, that are wet for at least part of the year. This type of wetland is ideal habitat for many types of wildlife, including ducks and pheasants (most of the continents ducks breed in this area), and has importance at both the continental and local levels. The Iowa portion of the Prairie Pothole Region corresponds roughly to zones 4, 5 and 8 in Figure 1. Choice set definitions may also be made based on the desire to limit the dimension of the models applied. ${ }^{9}$ This may lead one to consider restricted levels of market scope and increased site aggregation in an empirical model.

In order to illustrate the impact of these choice set decisions, we consider four models in this study, summarized by the varying degrees of scope and aggregation depicted in Figure 2. Model A represents the largest scope combined with the lowest level of aggregation, modeling the demand for recreation in the entire state and defining sites as the fifteen zones. ${ }^{10}$ Model B is conceptually similar to A, considering demand for recreation in the entire state, but with sites aggregated such that individuals chose from among five "mega-zones". Corresponding to Figure 1 , the aggregate sites are defined as $\{1,2,3\},\{4,5,8\},\{6,7,12\},\{9,10,11\}$, and $\{13,14,15\}$. Care 
has been taken to aggregate sites exhibiting similar geographical features, with the Prairie Pothole Region and east and west riverine wetland regions being grouped respectively. The final two definitions consider limiting the scope of the choice set, focusing on demand for recreation in the Prairie Pothole sites. Model C considers the demand for trips to the three disaggregate Prairie Pothole sites (zones 4, 5 and 8), while Model D combines these sites into a single good, resulting in a one-site model. ${ }^{11}$ In the restricted scope models, expenditures on visits to the other sites are included, but only as a component of the numeraire good. In this sense the restricted scope models represent higher degrees of horizontal aggregation, leaving out characteristics of the excluded sites. In the following sections we apply the KT model to each of these choice set definitions.

\section{EMPRICAL MODEL AND RESULTS}

Estimation of the KT model requires specification of the functional form for utility and the choice of distribution for the error terms. Following Phaneuf, Kling, and Herriges (2000) we choose as our utility function a version of the linear expenditure system. The consumer's direct utility function is given by

$$
u(\mathbf{x}, \mathbf{q}, \mathcal{\varepsilon})=\sum_{j=1}^{M} \Psi_{j}\left(q_{j}, \varepsilon_{j}\right) \ln \left(x_{j}+\theta\right)+\ln (z),
$$

where $\Psi_{j}$ is a quality index give by $\Psi_{j}\left(q_{j}, \varepsilon_{j}\right)=\exp \left(\delta_{0}+\delta_{1} p h_{j}+\varepsilon_{j}\right)$, and $p h_{j}$ is a site quality

variable equal to the pheasant count in the $j^{\text {th }}$ site if the individual indicated possession of a hunting or fishing license and equal to zero otherwise. The price of visiting zone $j$ for individual $i$ $\left(p_{i j}\right)$ was constructed by first establishing the roundtrip travel distance $\left(d_{i j}\right)$ and travel time $\left(t_{i j}\right)$ from their residence to the center of wetland zone $j$ using the software package PCMiler. The price was then constructed as $p_{i j}=0.22 d_{i j}+\left(0.33 w_{i}\right) t_{i j}$, where $w_{i}$ denotes the individual's marginal wage rate. Simple averages were used to construct price and quality variables for the aggregate mega-zones. 
The linear expenditure system is a somewhat restrictive specification for utility. The structure implies regime-specific demand equations of the form

$$
x_{j}=-\theta+\frac{\Psi_{j}}{1+\sum_{k \in \omega} \Psi_{k}} \frac{1}{p_{j}}\left(y+\sum_{k \in \omega} p_{k} \theta\right), j \in \omega,
$$

which is limiting in the types of substitution patterns captured between sites. This specification, however, combined with the assumption that the random terms are distributed independent and identical extreme value, makes it feasible to estimate relatively large dimensional models. ${ }^{12}$ The probability of observing an individual in demand regime $\omega$ has a closed form given by

$$
\pi_{\omega}=\exp \left(-\sum_{j \in \omega} \frac{g_{j}}{v}\right) \times \exp \left[-\sum_{i=1}^{M} \exp \left(-\frac{g_{j}}{v}\right)\right] \times a b s\left|J_{\omega}\right|,
$$

where

$$
g_{j}=\ln \left[\frac{p_{j}\left(x_{j}+\theta\right)}{y-\sum_{i=1}^{M} p_{i} x_{i}}\right]-\delta_{0}-\delta_{1} p h_{j}
$$

$J_{\omega}$ denotes the Jacobean transformation from $\left(\varepsilon_{1}, \ldots, \varepsilon_{M}\right)^{\prime}$ to $\left(x_{1}, \ldots, x_{M}\right)^{\prime}$, and $v$ is a scale parameter in the extreme value distribution. A probability term such as in (9) can be calculated for each individual in the sample, and maximum likelihood used to recover estimates of the utility function parameters.

The results from estimating each of the four models using the entire survey sample are presented in Table 1. All of parameters are found to be significantly different from zero at onepercent critical level. In and of themselves the parameters estimates are not interesting, except to note that the parameter associate with pheasant counts $\left(\delta_{1}\right)$ is positive and statistically significant. This indicates that pheasant counts positively influence both overall utility and the number of trips to a given region. A comparison across the models suggest that the scale and pheasant count 
parameter estimates are relatively stable, while there are noticeable differences in the estimates of $\theta$ and $\delta_{0}$.

Of greater interest are the welfare implications of the four models, presented in Table 2. We examine three scenarios, each reflecting different potential policy concerns. Scenario I examines the effect of policies that would increase pheasant counts statewide by twenty percent, whereas under Scenario II the pheasant counts are altered only in the Prairie Pothole Region. Scenario III attempts to assess the recreational value of the Prairie Pothole Region as a whole by examining the welfare effects of eliminating the resource. As previously noted, the various levels of scope and aggregation in the four models may affect the reported welfare measures.

The results in Table 2 indicate that, for this application, site aggregation consistently reduces the estimated welfare effects, regardless of the scope specification or the scenario being considered. The reductions range from just over eighteen percent in the case of Scenario III (for Models C versus D) to fifty-eight percent in the case of Scenario I (again for Models C versus D). These findings are consistent with earlier studies by Kaoru, Smith and Oiu (1995) and Feather (1994), though Parsons and Needelman (1992) typically found the aggregation bias to go in the opposite direction.

Limiting the geographical scope of the model also results in reduced welfare predictions. This is what one would expect for Scenario I. Models C and D, which restrict the scope of the market to the Prairie Pothole region, produce substantially lower welfare measures when compared to their statewide counterparts simply because they ignore the benefits of the improved pheasant counts outside of the Prairie Pothole Region. This is a direct result of the lack of characteristic data for the excluded sites, for which expenditures on are only included in the numeraire.

On the other hand, the explanation for the differences in the magnitudes between Scenarios II and III is less obvious. One a priori belief is that by limiting the scope of the market 
to the Prairie Pothole Region, we are excluding all other possible substitute wetland sites, making the modeled wetland sites more unique in the household's choice set. This would in turn increase the magnitudes of the welfare loss stemming from their elimination. Indeed, this is exactly what Parsons and Hauber (1998) found when they used spatial boundaries to limit the choice set. A second a priori belief is that the differences between the full and limited scope models should be small, since the numeraire good allows inclusion of expenditures on the non-modeled wetland sites, and the quality change occurs in all cases for sites which are fully modeled. ${ }^{13}$ The results seem to lean towards the second interpretation. . In particular, the welfare estimates from a limited scope models (C and D) are smaller in magnitude than those from their full scope counterparts (A and B respectively). Interestingly as well, the effect of this horizontal aggregation on sites into the numeraire good is consistent with the direction of the effect for the geographical aggregation mentioned above.

This would seem to be the opposite of the findings of Parsons and Hauber (1998). There is, however, a key distinction between the scope restrictions employed by these authors and the one being considered here. In their paper, geographical scope is defined uniquely for each individual in the sample, with sites included or excluded from the individual's choice set based on their distance from the individual's home. As a result, the sites that are first excluded from the choice set are those that are the furthest from the individual's home and, typically, represent low probability trips. This form of scope restriction is helpful when the analyst has available data on trips a large number of sites and wishes to reduces the dimensionality of the estimation problem. Parsons and Hauber (1998) show that excluding far flung sites from the choice set has little impact on the welfare estimates, with these sites are assigned a very low probability in the RUM framework.

The scope restrictions reflected in Table 2, however, are quite different. In moving from Models A and B to Models C and D, respectively, we are not excluding remote sites. On the contrary, for the majority of the sample we are excluding their primary wetland visitation sites, 
since most of the sample lives outside of the Prairie Pothole Region. This mimics what might occur in an empirical setting in which data are available on trips to a specific region, including visits by individual that live far from the sites of interest, but data are unavailable on sites that are the primary recreation areas for these remote individuals. By restricting the geographical scope, we are relying on both relatively few wetland sites to capture preferences for wetlands and a relatively small proportion of the sample, since individuals from outside the Prairie Pothole Region will be at corners in the KT model.

The findings in Parsons and Hauber (1998) partially emerge, however, if we restrict our analysis to individuals living in the Prairie Pothole Region. For these individuals, limiting the analysis to the Prairie Pothole sites (as in Models C and D) is comparable to using the spatial boundaries of Parsons and Hauber (1998). The resulting parameter estimates and welfare predictions are provided in Tables 3 and 4, respectively. For this restricted sample, we again find that aggregation reduces the estimated welfare effects in Scenarios I through III, with the reductions ranging from ten to sixty-one percent. However, the scope effects now move in the opposite directions. For Scenario I, we continue to find that the limited scope models understate the gains from statewide improvements in the pheasant counts. However, for Scenarios II and III, ignoring the substitute sites outside of the Prairie Pothole Region (as we do in Models C and D) results in welfare estimates that are up to seventy-two percent higher than if we include these substitute sites in the model.

\section{CONCLUSIONS AND DIRECTIONS}

The results presented above in many ways confirm the difficult nature of determining choice set definitions. In general, there is no obvious answer, leaving the analyst to make decisions based on his best judgement. A priori, we had expected site aggregation would not significantly affect the reported welfare measures, since the aggregation was done over fairly homogeneous resources. Yet, for this application aggregation consistently led to reduced welfare 
estimates. Conversely, our expectations were that scope limitation would affect welfare measures. Specifically, in limiting the scope of the market we are reducing the number of explicitly modeled substitutes, which would in turn make the modeled sites appear more unique, increasing the magnitudes of the estimated welfare effects. This result emerged when the scope restrictions were analogous to those employed by Parsons and Hauber (1998), providing spatial boundaries that eliminated remote sites. However, in the full sample, when the geographical scope restrictions eliminated sites frequently visited by much of the population, the welfare estimates were biased downwards. This perhaps supports the hypothesis that including horizontal substitutes in a numeraire good does not lead to large upward bias in welfare estimates, provided we are only considering changes in the attributes of explicitly modeled sites.

In the end, the choice set issue is also a data and data collection issue requiring pragmatic decisions by the analyst. The specification of choice sets remains as much art as science. We can never hope to gather information about all possible substitutes for all individuals. However, there are perhaps a few simple guidelines that can be followed. First, when gathering data on resource use, every effort should be made to survey not only resource users, but also non-users. This will enable us to model the "non-participation" decision, allowing an aggregation of all horizontal substitutes for the resource of interest. Next, it may be possible to geographically segment the sample population and identify the most likely substitutes for the resource of interest for each segment. This could then be included in the choice sets for the specific sub-sample. This would, or course, require econometric methods capable of handling this heterogeneous specification, proving a direction for further research in the KT model.

Finally, we note that, while the above analysis provides the first empirical investigation into site set definition using the KT framework rather than a single choice occasion RUM model, there are a number of other avenues for future research using the KT model. First, as suggested above, some of the results may be driven in part by the linear expenditure system's functional form, rather than underlying preferences. It would be useful to revisit this problem using a more 
flexible function form. Second, because analysis has generally focused on single choice occasion RUM models rather than fully utility consistent systems models, little attention has been paid to the micro foundations of aggregation in recreation demand. As we have done in this study, aggregation is typically accomplished via ad hoc averaging of component-site prices and quality measures. It is likely that different aggregation decisions and/or calculation of aggregate prices and quality would affect welfare results. Future research may call on the mature literature addressing aggregation in other areas of consumer choice (see, e.g., Varian 1992, section 9.3, Deaton and Muellbauer 1980, part 2, or Blackorby, Primont and Russell 1978) that can be readily applied within the KT framework. For example, Lupi and Feather (1998) suggest that there may be advantages to the aggregation of "collateral" sites to keep estimation tractable while allowing a larger market scope. This could be accomplished in the KT model by specifying the collateral sites as homothetically separable from the sites of primary interest, allowing for a theoretically consistent two-stage budgeting model. Under this specification, income would be first allocated between, say, remote trips, local trips and other goods, with a second stage modeling the allocation of local trip expenditures among the local sites. Consistent price and quantity indices could be constructed for the various commodity bundles, rather than relying upon average prices and total trips. ${ }^{14}$ Furthermore, the assumption of homothetic separability could be explicitly tested. 
Table 1: Estimation Results - Statewide Sample

\begin{tabular}{c|cccc}
\hline \hline \multirow{5}{*}{ Parameters } & \multicolumn{4}{c}{ Model } \\
\cline { 2 - 5 } & $\begin{array}{c}\text { Model A: } \\
\text { Statewide scope } \\
\text { 15 zones }\end{array}$ & $\begin{array}{c}\text { Model B: } \\
\text { Statewide scope } \\
\text { 5 mega-zones }\end{array}$ & $\begin{array}{c}\text { Model C: } \\
\text { Prairie Pothole } \\
\text { 3 zones }\end{array}$ & $\begin{array}{c}\text { Model D: } \\
\text { Prairie Pothole } \\
\text { 1 mega-zone }\end{array}$ \\
\hline$\theta$ & 5.92 & 6.17 & 6.86 & 7.39 \\
& $(0.15)$ & $(0.16)$ & $(0.44)$ & $(0.46)$ \\
& -6.03 & -5.30 & -5.91 & -5.14 \\
$\delta_{0}$ & $(0.04)$ & $(0.03)$ & $(0.11)$ & $(0.08)$ \\
& 0.009 & 0.007 & 0.008 & 0.006 \\
$\delta_{1}$ & $(<0.001)$ & $(<0.001)$ & $(0.001)$ & $(0.001)$ \\
& 0.58 & 0.54 & 0.51 & 0.46 \\
& $(0.01)$ & $(0.01)$ & $(0.02)$ & $(0.01)$ \\
\hline
\end{tabular}

Note: Standard errors in parenthesis. All parameter estimates are significantly different from zero at $1 \%$ level.

Table 2: Welfare Estimates - Statewide Sample

\begin{tabular}{|c|c|c|c|c|}
\hline \multirow[b]{2}{*}{ Welfare Scenarios: } & \multicolumn{4}{|c|}{ Model } \\
\hline & $\begin{array}{c}\text { Model A: } \\
\text { Statewide scope } \\
15 \text { zones }\end{array}$ & $\begin{array}{c}\text { Model B: } \\
\text { Statewide scope } \\
5 \text { mega-zones }\end{array}$ & $\begin{array}{c}\text { Model C: } \\
\text { Prairie Pothole } \\
3 \text { zones }\end{array}$ & $\begin{array}{c}\text { Model D: } \\
\text { Prairie Pothole } \\
1 \text { mega-zone }\end{array}$ \\
\hline $\begin{array}{l}\text { I. } 20 \% \text { increase in } \\
\text { pheasant counts } \\
\text { at all sites }\end{array}$ & $\$ 543$ & $\begin{array}{c}\$ 273 \\
(27)\end{array}$ & $\begin{array}{l}\$ 141 \\
(27)\end{array}$ & $\begin{array}{l}\$ 58 \\
(13)\end{array}$ \\
\hline $\begin{array}{l}\text { II. } 20 \% \text { increase in } \\
\text { prairie pothole } \\
\text { pheasant counts }\end{array}$ & $\$ 154$ & $\begin{array}{l}\$ 73 \\
(8)\end{array}$ & $\begin{array}{l}\$ 141 \\
(27)\end{array}$ & $\begin{array}{l}\$ 58 \\
(13)\end{array}$ \\
\hline $\begin{array}{l}\text { III. Loss of prairie } \\
\text { pothole region }\end{array}$ & $\$ 208$ & $\begin{array}{l}\$ 156 \\
(73)\end{array}$ & $\begin{array}{l}\$ 126 \\
(28)\end{array}$ & $\begin{array}{l}\$ 93 \\
(21)\end{array}$ \\
\hline
\end{tabular}

Notes: Welfare measures are in dollars per respondent per year. Standard errors on the welfare measures were constructed using a bootstrap procedure. ${ }^{15}$ 
Table 3: Estimation Results - Prairie Pothole Sample

\begin{tabular}{|c|c|c|c|c|}
\hline \multirow[b]{2}{*}{ Parameters } & \multicolumn{4}{|c|}{ Model } \\
\hline & $\begin{array}{c}\text { Model A: } \\
\text { Statewide scope } \\
15 \text { zones }\end{array}$ & $\begin{array}{c}\text { Model B: } \\
\text { Statewide scope } \\
5 \text { mega-zones }\end{array}$ & $\begin{array}{c}\text { Model C: } \\
\text { Prairie Pothole } \\
\text { 3 zones }\end{array}$ & $\begin{array}{c}\text { Model D: } \\
\text { Prairie Pothole } \\
1 \text { mega-zone }\end{array}$ \\
\hline$\theta$ & $\begin{array}{c}7.09 \\
(0.52)\end{array}$ & $\begin{array}{c}7.21 \\
(0.56)\end{array}$ & $\begin{array}{c}7.32 \\
(0.77)\end{array}$ & $\begin{array}{c}6.70 \\
(0.89)\end{array}$ \\
\hline$\delta_{0}$ & $\begin{array}{l}-5.79 \\
(0.11)\end{array}$ & $\begin{array}{l}-5.12 \\
(0.10)\end{array}$ & $\begin{array}{l}-5.81 \\
(0.16)\end{array}$ & $\begin{array}{l}-5.22 \\
(0.16)\end{array}$ \\
\hline$\delta_{1}$ & $\begin{array}{c}0.009 \\
(0.001)\end{array}$ & $\begin{array}{c}0.007 \\
(0.001)\end{array}$ & $\begin{array}{c}0.011 \\
(0.002)\end{array}$ & $\begin{array}{c}0.008 \\
(0.002)\end{array}$ \\
\hline$v$ & $\begin{array}{c}0.52 \\
(0.02)\end{array}$ & $\begin{array}{c}0.54 \\
(0.02)\end{array}$ & $\begin{array}{c}0.58 \\
(0.03)\end{array}$ & $\begin{array}{c}0.56 \\
(0.04)\end{array}$ \\
\hline
\end{tabular}

Note: Standard errors in parenthesis. All parameter estimates are significantly different from zero at $1 \%$ level.

Table 4: Welfare Estimates - Prairie Pothole Sample

\begin{tabular}{|c|c|c|c|c|}
\hline \multirow[b]{2}{*}{ Welfare Scenarios: } & \multicolumn{4}{|c|}{ Model } \\
\hline & $\begin{array}{c}\text { Model A: } \\
\text { Statewide scope } \\
15 \text { zones }\end{array}$ & $\begin{array}{c}\text { Model B: } \\
\text { Statewide scope } \\
5 \text { mega-zones }\end{array}$ & $\begin{array}{c}\text { Model C: } \\
\text { Prairie Pothole } \\
\text { 3 zones }\end{array}$ & $\begin{array}{c}\text { Model D: } \\
\text { Prairie Pothole } \\
1 \text { mega-zone }\end{array}$ \\
\hline $\begin{array}{l}\text { I. } 20 \% \text { increase in } \\
\text { pheasant counts } \\
\text { at all sites }\end{array}$ & $\$ 674$ & $\begin{array}{c}\$ 264 \\
(71)\end{array}$ & $\begin{array}{c}\$ 322 \\
(88)\end{array}$ & $\begin{array}{l}\$ 126 \\
(42)\end{array}$ \\
\hline $\begin{array}{l}\text { II. } 20 \% \text { increase in } \\
\text { prairie pothole } \\
\text { pheasant counts }\end{array}$ & $\$ 185$ & $\begin{array}{l}\$ 90 \\
(26)\end{array}$ & $\begin{array}{l}\$ 322 \\
(88)\end{array}$ & $\begin{array}{l}126 \\
(42)\end{array}$ \\
\hline $\begin{array}{l}\text { III. Loss of prairie } \\
\text { pothole region }\end{array}$ & $\$ 321$ & $\begin{array}{l}\$ 299 \\
(49)\end{array}$ & $\begin{array}{l}\$ 560 \\
(128)\end{array}$ & $\begin{array}{l}\$ 446 \\
(96)\end{array}$ \\
\hline
\end{tabular}

Notes: Welfare measures are in dollars per respondent per year. Standard errors on the welfare measures were constructed using a bootstrap procedure. 


\section{REFERENCES}

C. A. Azevedo. 1999. Linking Contingent Valuation and Travel Cost Data. Ph.D. dissertation, Department of Economics, Iowa State University.

C. Blackorby, D. Primont, and R. R. Russell. 1978. Duality, Separability, and Functional Structure: Theory and Economic Applications, New York: Elsevier North Holland, Inc.

N. E. Bockstael, W. M. Hanemann, and I. E. Strand. 1986. Measuring the Benefits of Water Quality Improvements Using Recreation Demand Models, Vol. 2, Washington, D.C.: U.S. Environmental Protection Agency, Office of Policy Analysis.

A. Deaton, and J. Muellbauer. 1980. Economics and Consumer Behavior, Cambridge: Cambridge University Press.

P. M. Feather. 1994. Sampling and aggregation issues in random utility model estimation. American Journal of Agricultural Economics 76: 772-780.

T. C. Haab and R. L. Hicks. 1997. Accounting for choice set endogeneity in random utility models of recreation demand. Journal of Environmental Economics and Management 34: 127-147.

T. C. Haab and R. L. Hicks. 2000. A survey of literature concerning choice set definition in recreation demand. Forthcoming, Marine Resource Economics.

W. M. Hanemann. 1978. A Methodological and Empirical Study of the Recreation Benefits from Water Quality Improvement. Ph.D. dissertation, Department of Economics, Harvard University. 
J. A. Herriges, C. L. Kling, and C. Azevedo. 1999. Ask a hypothetical question, get a valuable answer? Iowa State University Working paper, November, 1999.

J. A. Herriges, C. L. Kling, and D. J. Phaneuf. 1999. Corner solution models in recreation demand: A comparison of competing frameworks. Valuing Recreation and the Environment: Revealed Preference Methods in Theory and Practice, J. A. Herriges and C. L. Kling, eds., Aldershot: Edward Elgar Publishing, Ltd.

J. L. Horowitz. 1991. Modeling the choice of choice set inn discrete-choice random-utility models. Environment and Planning A 23: 1237-1246.

Y. Kaoru, V. K. Smith, and J. L. Oiu. 1995. Using random utility models to estimate the recreational value of estuarine resources. American Journal of Agricultural Economics 77: 141-151.

F. Lupi and P. M. Feather. 1998. Using partial site aggregation to reduce bias in random utility travel cost models. Water Resources Research 34: 395-3603.

E. R. Morey, R. D. Rowe, and M. Watson. 1993. A repeated nested logit model of Atlantic salmon fishing. American Journal of Agricultural Economics 75: 578-92.

G. R. Parson and A. B. Hauber. 1998. Spatial boundaries and choice set definition in random utility models of recreation demand. Land Economics 74: 32-48.

G. R. Parsons and M. J. Kealy. 1992. Randomly drawn opportunity sets in a random utility model of lake recreation. Land Economic 68: 93-106.

G. R. Parsons and M. S. Needelman. 1992. Site aggregation in a random utility model of recreation, Land Economics 68: 418-33. 
G. R. Parsons, A. J. Platinga, and K. J. Boyle. 1999. Narrow choice sets in random utility models of recreation demand. Forthcoming Land Economics.

T. Peters, W. L. Adamowicz, and P. C. Boxall. 1995. Influence of choice set considerations in modeling the benefits of improved water quality. Water Resources Research 31: 1781-1787.

D. J. Phaneuf, C. L. Kling, and J. A. Herriges. 1998. Valuing water quality improvements using revealed preference methods when corner solutions are present. American Journal of Agricultural Economics 80: 1025-1031.

D. J. Phaneuf, C. L. Kling, and J. A. Herriges. 2000. Estimation and welfare calculations in a generalized corner solution model with an application to recreation demand. Review of Economics and Statistics 82: 1-11.

W. D. Shaw and J. S. Shonkwiler. 1999. Brand choice and purchase frequency revisited: An application to recreation behavior, University of Nevada working paper.

H. R. Varian. 1992. Microeconomic Analysis, $3^{\text {rd }}$ edition, New York: W. W. Norton \& Company, Inc.

T. J. Wales and A. D. Woodland. 1983. Estimation of consumer demand systems with binding nonnegativity constraints. Journal of Econometrics 21: 263-85 (1983). 
Figure 1: Iowa Wetland Zones

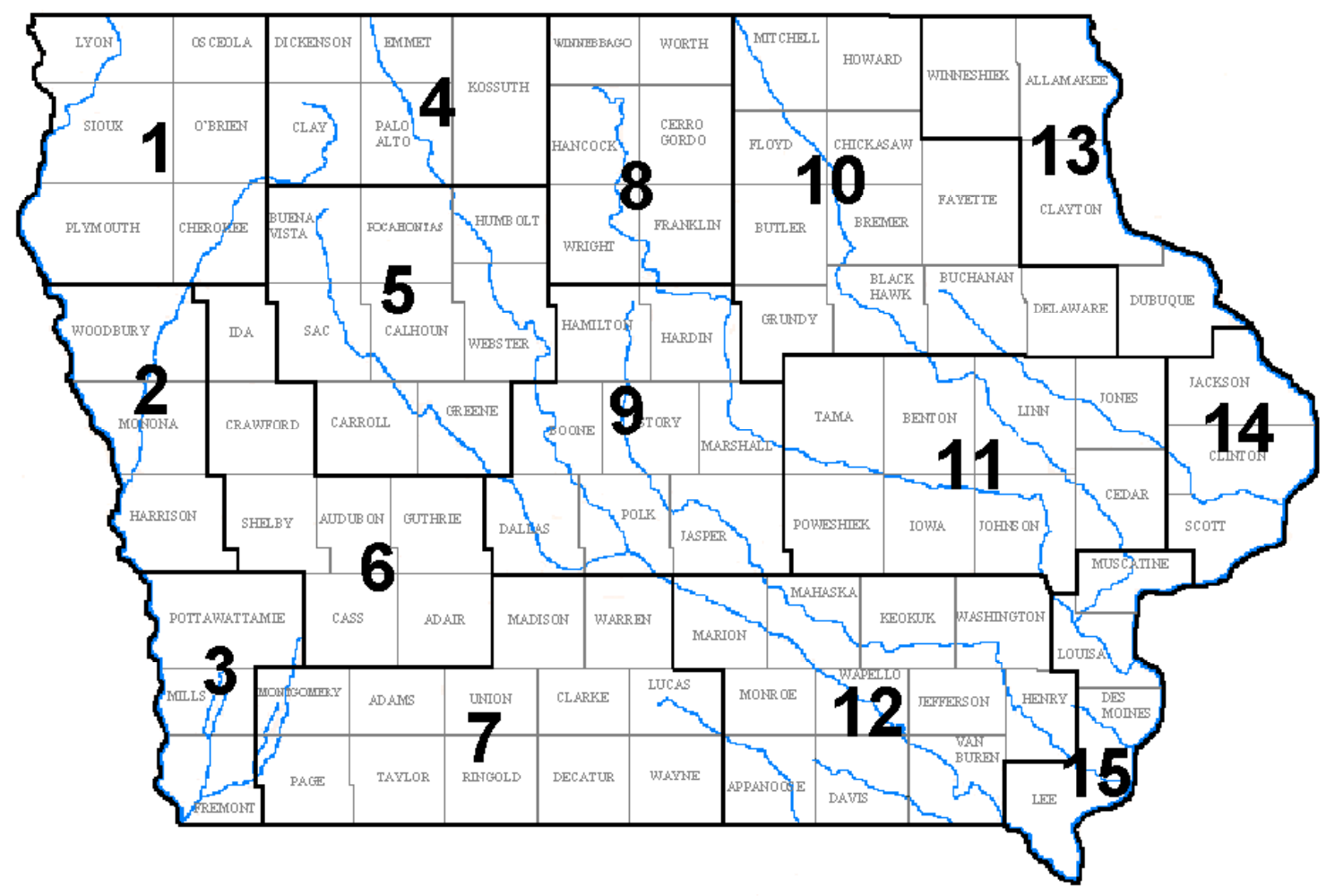

Figure 2: Choice Set Definition Options

\begin{tabular}{|c|c|c|}
\hline & \multicolumn{2}{|c|}{ Market Scope } \\
\hline .00 & $\begin{array}{c}\text { Model A } \\
15 \text { Sites } \\
\text { Iowa }\end{array}$ & $\begin{array}{c}\text { Model C } \\
3 \text { Sites } \\
\text { Prairie Pothole Region }\end{array}$ \\
\hline 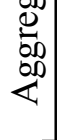 & $\begin{array}{l}\text { Model B } \\
5 \text { Sites } \\
\text { Iowa }\end{array}$ & $\begin{array}{c}\text { Model D } \\
1 \text { Site } \\
\text { Prairie Pothole Region }\end{array}$ \\
\hline
\end{tabular}




\section{FOOTNOTES}

* The authors would like to thank Cathy Kling and Kerry Smith, as well as participants in the Choice Set Definition Workshop sponsored by the National Marine Fisheries Service and two anonymous referees, for their helpful comments and discussion regarding earlier drafta of this paper. This research was supported in part by the U.S. Environmental Protection Agency and by the Western Regional Research Project W-133. Although the research described in this article has been funded in part by the United States Environmental Protection Agency through R826615-011 to the authors, it has not been subject to the Agency's required peer review policy and therefore does not necessarily reflect the views of the Agency and no official endorsement should be inferred. All remaining errors are our own.

${ }^{* *}$ Corresponding author.

${ }^{1}$ See Parsons and Hauber (1998) for an excellent discussion of the use of spatial boundaries in choice set definitions, including the risk of setting these boundaries too tight.

${ }^{2}$ See, e.g., Parsons and Needelman (1992), and Kaoru, Smith and Oiu (1995).

${ }^{3}$ See Haab and Hicks (2000) in this issue for a review of the literature on choice set definition issues.

${ }^{4}$ Bockstael, Hanemann, and Strand (1986) suggest using the model for addressing corner solutions in recreation demand, while Phaneuf, Kling, and Herriges (2000) provide an application. See Phaneuf, Kling, and Herriges (2000) for a more complete description of the Kuhn-Tucker model.

${ }^{5}$ In particular, it is assumed that $u_{z \varepsilon}=0, \partial u_{j} / \partial \varepsilon_{k}=0 \forall k \neq j$ and $\partial u_{j} / \partial \varepsilon_{j}>0 \forall j$.

${ }^{6}$ While Iowa wetlands obviously do not fall into category of marine resources, the choice set definition challenges associated with this data set are similar to those facing analysts using marine recreation data. The survey itself is part of a larger project to examine the value of 
wetlands in Iowa. For details on the survey process and discussion of the project's wider goals, including wetland definitions and discussion of the importance of wetland conservation, see Azevedo (1999) or Herriges, Kling, and Azevdo (1999).

${ }^{7}$ A series of focus groups and a pre-test of 600 Iowa households were used to develop the survey instrument prior to its final administration to the full sample of 6000 households. The sample was stratified to insure users were included in the final survey sample, with 4000 households drawn from the general residential population and 2000 households drawn from fishing and hunting license holders. An overall survey response rate of 58\% was achieved among the deliverable surveys. See Azevedo (1999) for additional details.

${ }^{8}$ While the zones were specified along county boundaries, they were also selected so as to reflect broadly homogeneous wetland types within the state, such as the riverine wetlands along the eastern and western borders of the state (i.e., zones $1,2,3,13,14$, and 15) versus the prairie pothole wetlands in north-central Iowa (zones 4,5 , and 8 ).

${ }^{9}$ For example, in our application of the KT model to the demand for Wisconsin Great Lakes fishing trips (see Phaneuf, Kling and Herriges 2000), we aggregate data on 22 possible destinations to 4 sites. This was done primarily to reduce the dimension of the model being estimated.

${ }^{10}$ We note that, due the nature of the original survey instrument, we only have available data from sites that have already been substantially aggregated. Thus, it is not all together proper to call Model A a disaggregate model, except in relation to the others.

${ }^{11}$ It is worth noting again that while the aggregation restrictions used in the KT model are similar to those often used in RUM's, the scope restrictions are somewhat different. Analysts employing the standard RUM framework have typically restricted the choice set for the individual by some criteria, allowing the choice sets to potentially be of different magnitudes across individuals, while in this paper KT model's choice set has been restricted to be the same 
for all individuals. Thus, it is the geographic scope of the resource to be examined in detail, rather than the individual's geographic scope. Another perspective on the scope restrictions considered in this paper comes from noting that the Prairie Pothole wetlands are different from the riverine and small pond wetlands elsewhere in the state. Thus, the scope restriction employed here is analogous to say excluding inland fisheries when studying marine fisheries along the East Coast. Finally, we note that, conceptually, there is nothing preventing the KT model from employing individual specific scope restrictions. The computing coding would simply be more complex.

${ }^{12}$ In addition, the level of restriction implied by the LES system is similar to the use of linear functional forms in most applications of random utility models. The KT model provides the added benefit that welfare measures reflect seasonal, rather than the loosely defined choice occasion, measures. The extreme value distribution was chosen in this case for simplicity. A generalized extreme value distribution could have been employed as well, at the expense of more time consuming in the welfare calculation procedures. Expressions for the Jacobean transformation terms, as well as example programs written in GAUSS for estimation and welfare calculations of various dimensional KT models using the LES utility function, are available from the authors upon request.

${ }^{13}$ We appreciate the comments on an anonymous reviewer, who clarified this second point.

${ }^{14}$ Shaw and Shonkwiler (1999) have suggested an alternative approach to constructing consistent site aggregates, relying instead on Hicksian separability. In particular, as travel costs are typical assumed to be proportional to round-trip travel time and/or travel distance, the price of visiting sites moves essentially in a fixed proportion with changes in costs per mile, satisfying the conditions for Hicksian aggregation. Their suggestion is to use total miles driven as the means of aggregating multiple trips, rather than total number of trips. 
${ }^{15}$ Standard errors were not constructed for the 15 -good model due to time limitations in completing the manuscript for this special issue. Computation of the standard errors in case, while technically feasible, remains time consuming. 


\title{
WHAT'S THE USE? WELFARE ESTIMATES FROM REVEALED PreferenCe Models When Weak COMPlementarity Does NOT HOLD
}

\author{
by \\ Joseph A. HERriges AND CATHERINE L. KLING \\ Department of Economics, Iowa State University \\ and \\ DANIEL J. PHANEUF \\ Department of Agricultural and Resource Economics, North Carolina State University
}

January 13,2000 


\section{INTRODUCTION}

A large literature on the valuation of environmental quality changes based upon behavioral data on use of the environment has developed over the past thirty years. These models have been variously referred to as recreation demand, travel cost, and/or revealed preference models and have employed a variety of demand and /or random utility estimation techniques. The purpose of these models has been, almost without exception, to estimate the value of the direct use of these resources. Thus, the surplus measures estimated have often been referred to as "use" values.

Mäler's (1974) concept of weak complementarity has periodically been invoked to justify the focus on use values. In brief, the property of weak complementarity implies that if an individual does not directly use an environmental good, he or she places no value on changes in the quality attributes of that good. Hence, there is no value associated with environmental quality except that which accrues from using the good. Most discussions of weak complementarity begin and end with comments along these lines. Thus, although numerous revealed preference (RP) models invoke weak complementarity, few papers give serious attention to empirical specification of RP models or their interpretation in its absence.

The purpose of this paper is to consider the measurement of welfare from revealed preference models in which weak complementary does not hold. It is important that we note at the outset that pure "existence value" (as we will define it later) simply cannot be estimated from revealed preference data. This well-understood point is not in contention here. Rather, we are simply interested in what complications arise to computing welfare estimates from revealed preference models in the absence of weak complementarity. For example, if weak complementarity does not hold, what is the appropriate interpretation of the traditionally computed welfare measures (i.e., areas under the estimated demand curve)? Does the lack of weak complementarity bias the estimate of this value? What interpretation might the analyst give to the residual value that is present even when demand is zero? Should the welfare analyst impose 
weak complementarity for estimation purposes even when he or she suspects its absence?

A number of authors have decomposed total value into use value and existence value associated with changes in environmental quality relying upon weak complementarity to define the two pieces (Madariaga and McConnell, 1987). Freeman (1993) identifies three components of value: use value, pure existence value (value placed on environmental quality completely independent of use), and non-use value (value the individual gets that is related to use, but which does not disappear when the good is not consumed). Hanemann (1988) defines non-use and use value, but employs a definition that does not invoke weak complementarity to distinguish the two. In this paper, we build on these definitions with a specific focus on identifying the pieces of total value that are recoverable or at least potentially recoverable from revealed preference approaches (and correspondingly, which pieces are not). Our motivation for revisiting this theme is pragmatic. As noted above, typical application of revealed preference (e.ge. RUM's) models have maintained the assumption of weak complementarity, eliminating the need for discussion on how benefits measures from behavioral data should be interpreted. In contrast, recent applications of the Kuhn-Tucker model (see e.g. Phaneuf, et al., 2000) have not a priori assumed weak complementarity in the functional form for preferences, allowing for the possibility that weak complementarity will not hold for the estimated preference structure. This has necessitated discussion on what is the proper welfare measures for this class of revealed preference model.

After developing the concepts in the next two sections, we empirically investigate these issues using a data set on wetland usage in the state of Iowa. Six thousand residents were sampled in the spring of 1998. Data on the number of visits they took to wetland areas in the state and the costs of those visits were collected, along with a variety of socioeconomic data and other relevant information. This data set provides a rich basis upon which to investigate these issues.

\section{THE COMPONENTS OF VALUE EXPOSED BY REVEALED PREFERENCE DATA}

As noted above, numerous authors have defined and decomposed value into various

pieces. Here, we adopt and modify slightly the model suggested by Hanemann (1988). The main 
purpose for the decomposition is to aid our understanding of the inherent limitations on the empirical welfare measures that can be extracted from revealed preference data.

The decomposition process begins by specifying a general structure of consumer preferences that will accommodate both traditional use value and the more controversial indirect use and existence value components. Hanemann (1988) assumes that the direct utility function takes the form

$$
U=T[u(\mathbf{x}, q), q]
$$

where $\mathbf{x}$ is a vector of private market goods and $q$ (a scalar) is a public good (e.g., environmental amenity) taken as given by the individual consumer; $T(u, q)$ is increasing in $u$ and $q$; and $u(\mathbf{x}, q)$ is increasing and quasi-concave in $\mathbf{x}$ and $q$. Note that $q$ enters utility in two separate places, in a group with the private goods $(\mathbf{x})$ and separably on its own. Importantly, the marginal rates of substitution between observed consumption bundles (the $x$ 's) will be independent of the second component of the utility function and thus cannot reveal information about the value of changes in that portion of the function. ${ }^{1}$

The corresponding indirect utility function is then given by:

$$
\begin{aligned}
V(\mathbf{p}, q, y) & \equiv \underset{\mathbf{x}}{\operatorname{Max}}\left\{T[u(\mathbf{x}, q), q] \mid \mathbf{p}^{\prime} \mathbf{x} \leq y\right\} \\
& =T\left[\operatorname{Max}\left\{u(\mathbf{x}, q) \mid \mathbf{p}^{\prime} \mathbf{x} \leq y\right\}, q\right] \\
& =T[v(\mathbf{p}, q, y), q]
\end{aligned}
$$

where $v(\mathbf{p}, q, y) \equiv \underset{\mathbf{x}}{\operatorname{Max}}\left\{u(\mathbf{x}, q) \mid \mathbf{p}^{\prime} \mathbf{x} \leq y\right\}$. Again, as the second line of equation (2) emphasizes, all of the interactions between the consumer's activity in the marketplace (including recreational demand) and the public good $q$ are revealed through $v(\mathbf{p}, q, y)$ and independent of the form of $T(\cdot, q)$. Consequently, revealed preference data simply cannot be used to estimate the form of $T(\cdot, q)$

Finally, we can specify the corresponding expenditure function as: 


$$
\begin{aligned}
E(\mathbf{p}, q, \tilde{U}) & \equiv \operatorname{Min}_{\mathbf{x}}\left\{\mathbf{p}^{\prime} \mathbf{x} \mid T[u(\mathbf{x}, q), q] \geq \tilde{U}\right\} \\
& =\operatorname{Min}_{\mathbf{x}}\left\{\mathbf{p}^{\prime} \mathbf{x} \mid u(\mathbf{x}, q) \geq \tilde{u}(\tilde{U}, q)\right\} \\
& =e[\mathbf{p}, q, \tilde{u}(\tilde{U}, q)] .
\end{aligned}
$$

where $\tilde{u}(\tilde{U}, q)$ is defined implicitly by $T[\tilde{u}, q]=\tilde{U}$ and $e(\mathbf{p}, q, \tilde{u}) \equiv \operatorname{Min}_{\mathbf{x}}\left\{\mathbf{p}^{\prime} \mathbf{x} \mid u(\mathbf{x}, q) \geq \tilde{u}\right\}$ denotes the standard expenditure function. ${ }^{2}$ Note that the utility level at which the traditional expenditure function is evaluated is adjusted for the second role of $q$ in preferences and that generally $E(\mathbf{p}, q, \tilde{u}) \neq e(\mathbf{p}, q, \tilde{u})$

Turning to welfare valuations, it is natural to define the total compensating variation $\left(C^{T}\right)$ for change in the level of the resource from $q^{0}$ to $q^{1}$ as

$$
T\left[v\left(\mathbf{p}^{0}, q^{0}, y\right), q^{0}\right]=T\left[v\left(\mathbf{p}^{0}, q^{1}, y-C^{T}\right), q^{1}\right]
$$

Hanemann (1988) suggests the following decomposition:

$$
C^{T}=C^{R}+\tilde{C}
$$

where $C^{R}$ is implicitly defined by

$$
T\left[v\left(\mathbf{p}^{0}, q^{0}, y\right), q^{0}\right]=T\left[v\left(\mathbf{p}^{0}, q^{1}, y-C^{R}\right), q^{0}\right]
$$

and $\tilde{C}$ satisfies

$$
T\left[v\left(\mathbf{p}^{0}, q^{0}, y\right), q^{0}\right]=T\left[v\left(\mathbf{p}^{0}, q^{0}, y-\tilde{C}\right), q^{1}\right]
$$

Notice that $C^{R}$ compensates for the impact that the change in $q$ has on the first argument in $T(\cdot, \cdot)$, whereas $\tilde{C}$ compensates for the impact of the change on the second argument of $T(\cdot, \cdot)$.

Unfortunately, the decomposition in (5) holds only if the marginal utility of income is constant. ${ }^{3}$ However, the following modified version of equation (5) can be used:

$$
C^{T}=C^{R}+C^{E}
$$

where $C^{E}$ is implicitly defined by 


$$
T\left[v\left(\mathbf{p}^{0}, q^{1}, y^{R}\right), q^{0}\right]=T\left[v\left(\mathbf{p}^{0}, q^{1}, y^{R}-C^{E}\right), q^{1}\right] .
$$

and $y^{R} \equiv y-C^{R}$. Comparing equations (4), (6), and (9), it is clear that we have is a sequential compensation for the change in $q$, with:

$$
\begin{aligned}
T\left[v\left(\mathbf{p}^{0}, q^{0}, y\right), q^{0}\right] & =T\left[v\left(\mathbf{p}^{0}, q^{1}, y-C^{R}\right), q^{0}\right] \\
& =T\left[v\left(\mathbf{p}^{0}, q^{1}, y-C^{R}-C^{E}\right), q^{1}\right] .
\end{aligned}
$$

The compensation $C^{R}$ in the first line of equation (10) is used to offset the impact that the change in $q$ has on $v(\mathbf{p}, q, y)$. In contrast, $C^{E}$ denotes the additional compensation required to make the individual whole; i.e., compensating for the impact that the change in $q$ has on the second argument in $T(\cdot, q)$ given $C^{R}$ has already been paid. ${ }^{4}$ Throughout the remainder of the paper, we refer to $C^{R}$ as the revealable portion of compensation and $C^{E}$ as existence value. ${ }^{5}$ Note that this definition of existence value makes no use of the property of weak complementarity (as others have often done in the definition of existence value). It is worth reemphasizing one final time that this piece of value cannot be recovered from revealed preference data. This inherent limitation of revealed preference is well known and will receive no further attention here. ${ }^{6}$

Rather, our focus will turn to the remaining piece, which we have termed $C^{R}$. This piece is of particular interest because it describes the portion of preferences about which we can potentially infer something from revealed preference data. The next question is how much of $C^{R}$ can be inferred from revealed preference data. This is where Mäler's concept of weak complementarity becomes helpful. We note that $C^{R}$ can itself be decomposed into pieces as follows:

$$
C^{R}=C^{U}+C^{I U}
$$

with $C^{I U}$ implicitly defined by

$$
v\left[\tilde{\mathbf{p}}\left(q^{0}\right), q^{0}, y\right]=v\left[\tilde{\mathbf{p}}\left(q^{1}\right), q^{1}, y-C^{I U}\right],
$$


where $\tilde{\mathbf{p}}(q)$ denotes the price vector at which $\mathbf{x}=\mathbf{0}$ (in general dependant on $q$ ), and $C^{U} \equiv C^{R}-C^{I U}$. It seems intuitive to refer to $C^{I U}$ as the "indirect use" value, as it represents welfare changes when the associated market goods are not in use, whereas $C^{U}$ corresponds to direct "use" value. ${ }^{7}$ The components $C^{U}$ and $C^{I U}$ can be equivalently defined in terms of the expenditure function as: ${ }^{8}$

$$
C^{U}=\left\{e\left[\mathbf{p}, q^{0}, u^{0}\right]-e\left[\tilde{\mathbf{p}}\left(q^{0}\right), q^{0}, u^{0}\right]\right\}-\left\{e\left[\mathbf{p}, q^{1}, u^{0}\right]-e\left[\tilde{\mathbf{p}}\left(q^{1}\right), q^{1}, u^{0}\right]\right\}
$$

and

$$
C^{I U}=e\left[\tilde{\mathbf{p}}\left(q^{0}\right), q^{0}, u^{0}\right]-e\left[\tilde{\mathbf{p}}\left(q^{1}\right), q^{1}, u^{0}\right]
$$

where $u^{0}=v\left(\mathbf{p}, q^{0}, y\right)$. Mäler's assumption of weak complementarity recognizes that if

$$
v\left[\tilde{\mathbf{p}}\left(q^{0}\right), q^{0}, y\right]=v\left[\tilde{\mathbf{p}}\left(q^{1}\right), q^{1}, y\right]
$$

then $C^{I U}=0$ and $C^{U}=C^{R}$, capturing all of the value of a change in $q$. Further, $C^{U}$ can be represented as areas under Hicksian demands

$$
C^{U}=\int_{p_{1}^{0}}^{\tilde{p}_{1}\left(q^{1}\right)} x_{1}\left(p_{1}, \mathbf{p}_{-1}, q^{1}, u^{0}\right) d p_{1}-\int_{p_{1}^{0}}^{\tilde{p}_{1}\left(q^{0}\right)} x_{1}\left(p_{1}, \mathbf{p}_{-1}, q^{0}, u^{0}\right) d p_{1}
$$

where $\mathbf{p}_{-1}$ represents the vector of all prices except for good 1 and $x_{1}\left(p_{1}, \mathbf{p}_{-1}, q^{1}, u^{0}\right)$ denotes the Hicksian demand for good 1 . This is a very handy result for applied welfare analysts as it means that once a demand function is estimated, the welfare change associated with a change in quality can be computed via $(16)^{9}$. There is no need to explicitly specify the underlying expenditure or indirect utility function. Of course, if the analyst knows the underlying expenditure or indirect utility function, they can be used directly to compute $C^{U}$.

However, it is the circumstances under which (15) does not hold that interest us here. In this case, the computation of $C^{R}$ does not equal $C^{U}$ from (16). The question then becomes which, if either, of these two welfare measures is meaningful? To answer this question, we need a 
better understanding of why weak complementarity might fail to hold in an empirical setting. In the next section, we explore this issue by considering possible explanations for violations of weak complementarity.

\section{RATIONALE FOR OBSERVING VIOLATIONS OF WEAK COMPLEMENTARITY}

Violations of weak complementarity have rarely been observed in empirical studies of recreation demand largely because the dominant modeling framework (i.e., RUM's) implicitly imposes it. However, in recent efforts to employ the Kuhn-Tucker approach of Wales and Woodland (1983) to recreation demand, weak complementarity has been soundly rejected as a restriction on preferences. ${ }^{10}$ In this section, we consider three possible rationales for these apparent violations and examine the implications for applied research. First, there may be one or more goods that form the set of goods that are weakly complementary to $q$. Madariaga and McConnell (1987) consider this possibility when they note that their definition of existence value includes off site use values. Bockstael and Kling (1988) derive the appropriate welfare measures if all of the weakly complementary demands are estimated and used for welfare computation. If the analyst has included only one of the goods in the empirical model, the omitted variables may show up as a rejection of weak complementarity. Second, the absence of weak complementarity may be a direct result of the individual's preference for environmental quality. For example, in the context of the household production framework, environmental quality may be an essential good in the production of environmental services, whereas $x$ may not be. ${ }^{11}$ Finally, estimation of preferences which are not weakly complementary to $q$ may stem from econometric issues such as model specification and/or measurement errors. In this section, we discuss each of these explanations in turn. We consider their implications for specifying empirical models of revealed preferences as well as the appropriate computation and interpretation of welfare measures coming from such models.

\subsection{Weak Complementarity with Sets of Goods - An Omitted Variables Story}

Bockstael and Kling (1988) derive welfare measures for changes in environmental 
quality when quality is weakly complementary to a set of goods. Suppose there are two goods that are weak complements to $q, x_{1}$ and $x_{2}$. This means that when both $x_{1}$ and $x_{2}$ equal zero, the marginal utility of $q$ is also zero. Bockstael and Kling demonstrate that in this case, the correct welfare measure for a change in $q$ can be written as the sum of areas under demand curves ${ }^{12}$

$$
\begin{aligned}
C^{R} & =C^{U} \\
& =\left[\int_{p_{1}^{0}}^{\tilde{p}_{1}\left(q^{1}\right)} x_{1}\left(p_{1}, p_{2}^{0}, q^{1}, u^{0}\right) d p_{1}-\int_{p_{1}^{0}}^{\tilde{p}_{1}\left(q^{0}\right)} x_{1}\left(p_{1}, p_{2}^{0}, q^{0}, u^{0}\right) d p_{1}\right] \\
& +\left[\int_{p_{2}^{0}}^{\tilde{p}_{2}\left(q^{1}\right)} x_{2}\left[\tilde{p}_{1}\left(q^{1}\right), p_{2}, q^{1}, u^{0}\right] d p_{2}-\int_{p_{2}^{0}}^{\tilde{p}_{2}\left(q^{0}\right)} x_{2}\left[\tilde{p}_{1}\left(q^{0}\right), p_{2}, q^{0}, u^{0}\right] d p_{2}\right] \\
& =C_{1}^{U}+\tilde{C}_{2}^{U}
\end{aligned}
$$

where

$$
C_{1}^{U}=\int_{p_{1}^{0}}^{\tilde{p}_{1}\left(q^{1}\right)} x_{1}\left(p_{1}, p_{2}^{0}, q^{1}, u^{0}\right) d p_{1}-\int_{p_{1}^{0}}^{\tilde{p}_{1}\left(q^{0}\right)} x_{1}\left(p_{1}, p_{2}^{0}, q^{0}, u^{0}\right) d p_{1}
$$

and

$$
\tilde{C}_{2}^{U}=\int_{p_{2}^{0}}^{\tilde{p}_{2}\left(q^{1}\right)} x_{2}\left[\tilde{p}_{1}\left(q^{1}\right), p_{2}, q^{1}, u^{0}\right] d p_{2}-\int_{p_{2}^{0}}^{\tilde{p}_{2}\left(q^{0}\right)} x_{2}\left[\tilde{p}_{1}\left(q^{0}\right), p_{2}, q^{0}, u^{0}\right] d p_{2} .
$$

In terms of expenditure functions, $C^{R}$ can be expressed equivalently as

$$
\begin{aligned}
C^{R} & =C^{U} \\
& =e\left(p_{1}^{0}, p_{2}^{0}, q^{0}, u^{0}\right)-e\left(p_{1}^{0}, p_{2}^{0}, q^{1}, u^{0}\right)
\end{aligned}
$$

Our point of departure is to consider what happens when the analyst either does not know or cannot measure $x_{2}$ and thus cannot estimate the second demand function. Further, the analyst cannot include the price of $x_{2}$ in the estimating equation for $x_{1}$, possibly generating biased coefficient estimates for the first demand equation, depending of course on the correlation patterns between the omitted variable and the included ones.

What are the implications of this mis-specification for welfare measurement? Obviously, the analyst cannot estimate the sum of areas as represented in (17) since $x_{2}$ is unknown. However, the 
analyst might be able to recover an unbiased estimate of $C_{1}^{U}$ in (18). Further, the analyst might be able to use knowledge of the form of the expenditure function underlying the estimated demand model to compute some part of $C^{R}$. We are interested in identifying the circumstances under which $C_{1}^{U}$ and/or $C^{R}$ might be recovered from RP estimates. As suggested earlier, the answer depends on the correlation patterns between the omitted and included variables.

Suppose first that the omitted price of good 2 is not correlated with any of the other independent variables in the first demand equation. If $x_{2}$ represents magazines, books, videos, and/or other non-consumption items related to $q$, the assumption of complete independence may be quite reasonable (in fact, $p_{2}$ might be nearly constant across the sample). For intuition in considering the econometric implications, suppose the true demands for both goods are linear; i.e.,

$$
x_{i}=\alpha_{i}+\beta_{i} p_{i}+\gamma_{i} p_{j}+\delta_{i} q \quad i=1,2 ; j \neq i
$$

Standard omitted variables results indicate that the estimation of the demand for $x_{1}$ in this circumstance will result in unbiased coefficient estimates for each of the slope parameters, but a biased constant term with

$$
E\left(\alpha_{1}\right)=\alpha_{1}+\beta_{2} \bar{p}_{2}^{0}
$$

where $\bar{p}_{2}^{0}$ is the sample average price of $x_{2}$. The sign of the bias to the intercept will depend upon the relationship between $x_{1}$ and $x_{2}$; if they are substitutes, the constant term will be biased upwards, if they are complements the bias will be downwards.

What are the implications for welfare measurement? Because each individual's $p_{2}$ is unknown and cannot be included in the estimating equation, the demand equation is conditioned on the sample average $\bar{p}_{2}^{0}$ rather than the individual's actual $p_{2}$. The estimated welfare for each individual can be expressed as

$$
\hat{C}_{1}^{U}=\int_{p_{1}^{0}}^{\tilde{p}_{1}\left(q^{1}\right)} x_{1}\left(p_{1}, \bar{p}_{2}^{0}, q^{1}, u^{0}\right) d p_{1}-\int_{p_{1}^{0}}^{\tilde{p}_{1}\left(q^{0}\right)} x_{1}\left(p_{1}, \bar{p}_{2}^{0}, q^{0}, u^{0}\right) d p_{1}
$$


yielding a bias of

$$
\begin{aligned}
\operatorname{bias}_{1} & =\left[\int_{p_{1}^{0}}^{\tilde{p}_{1}\left(q^{1}\right)} x_{1}\left(p_{1}, \bar{p}_{2}^{0}, q^{1}, u^{0}\right) d p_{1}-\int_{p_{1}^{0}}^{\tilde{p}_{1}\left(q^{0}\right)} x_{1}\left(p_{1}, \bar{p}_{2}^{0}, q^{0}, u^{0}\right) d p_{1}\right] \\
& -\left[\int_{p_{1}^{0}}^{\tilde{p}_{1}\left(q^{1}\right)} x_{1}\left(p_{1}, p_{2}^{0}, q^{1}, u^{0}\right) d p_{1}-\int_{p_{1}^{0}}^{\tilde{p}_{1}\left(q^{0}\right)} x_{1}\left(p_{1}, p_{2}^{0}, q^{0}, u^{0}\right) d p_{1}\right]
\end{aligned}
$$

Unfortunately, the sign of this bias is generally indeterminate both for any individual and when summed over the sample. ${ }^{13}$ However, two conditions under which this bias will be small are clear: (1) when $p_{2}$ does not vary across the sample then $p_{2}^{0}=\bar{p}_{2}^{0}$ and there is no bias, and (2) when $\partial x_{1} / \partial p_{2}=0$ or is small, the bias will also be nonexistent or small.

We now turn to the prospects in this case for the estimation of $C^{R}$. Recall that $C^{R}$ can be written as in (20) as the difference between two expenditure functions. Are these recoverable? The answer is yes, but like the recovery of $C_{1}^{U}$, they can only be evaluated at the "wrong" value of $p_{2}$. To see why, note that if we know the Hicksian demand (as required to compute $C_{1}^{U}$ ), we can integrate it over price to recover the expenditure function. Like the demand, the expenditure function will be a function of the own price $\left(p_{1}\right), q$, and the sample average of the price of the second good $\left(\bar{p}_{2}^{0}\right)$ (embedded in the parameter estimates). Thus, computation of the difference in expenditure functions evaluated at the current own price and changes in $q$ is equivalent to

$$
\begin{aligned}
\hat{C}^{R} & =\hat{C}^{U} \\
& =e\left(p_{1}^{0}, \bar{p}_{2}^{0}, q^{0}, u^{0}\right)-e\left(p_{1}^{0}, \bar{p}_{2}^{0}, q^{1}, u^{0}\right)
\end{aligned}
$$

yielding a bias of

$$
\operatorname{bias}_{R}=\left[e\left(p_{1}^{0}, \bar{p}_{2}^{0}, q^{0}, u^{0}\right)-e\left(p_{1}^{0}, \bar{p}_{2}^{0}, q^{1}, u^{0}\right)\right]-\left[e\left(p_{1}^{0}, p_{2}^{0}, q^{0}, u^{0}\right)-e\left(p_{1}^{0}, p_{2}^{0}, q^{1}, u^{0}\right)\right]
$$

Unfortunately, the sign and magnitude of this bias is again indeterminate. Under very restrictive conditions one might be able to estimate the correct structure for the expenditure function and obtain unbiased estimates of $C^{U} \cdot{ }^{14}$ However, these conditions are unlikely to hold in practice and we would 
recommend instead that $\hat{C}_{1}^{U}$ be computed and report as what it is, a measure of the use value stemming from the combined use of $x_{1}$ and $q$, and acknowledging the missing components $\tilde{C}_{2}^{U}$ and $C^{E}$

Now consider the case where the omitted price of good 2 is perfectly correlated with one of the variables in the $x_{2}$ equation. A likely candidate would seem to be $p_{1}$. In particular, if $x_{1}$ represents visits to a recreation site for the purpose of fishing and $x_{2}$ represents visits to the same site with the purpose of swimming, hiking, or any other activity, the perfect correlation of prices is quite likely. Following Bockstael and Kling (1988), suppose the prices of the two commodities are related in a linear fashion, so that

$$
p_{2}=\phi_{1}+\phi_{2} p_{1}
$$

where $\phi_{1}$ and $\phi_{2}$ are constants. In this case, estimation of the linear model in (21) omitting $p_{2}$ will yield the following properties of the estimated coefficients

$$
E\left(\hat{\alpha}_{1}\right)=\alpha_{1}+\beta_{2} \phi_{1}
$$

and

$$
E\left(\hat{\beta}_{1}\right)=\beta_{1}+\beta_{2} \phi_{2}
$$

In this case, the relationship between $p_{1}$ and $p_{2}$ is embedded in the estimated demand function for $x_{1}$ since the estimated coefficients incorporate the relationship. What does this mean for the recovery of $C_{1}^{U}$ and $C^{R}=C^{U}$ ? As Bockstael and Kling (1988, p. 660) note in a similar situation, by varying $p_{1}$, we are implicitly varying $p_{2}$ as well. Thus, when constructing $C_{1}^{U}$ using equation (18), one is in fact computing

$$
\widehat{C}_{1}^{U}=\int_{p} x_{1}\left(p_{1}, p_{2}, q^{1}, u^{0}\right) d t-\int_{p} x_{1}\left(p_{1}, p_{2}, q^{0}, u^{0}\right) d t
$$

where the price path $P$ corresponds to $p_{1}=t$ and $p_{2}=\phi_{1}+\phi_{2} t$. The remaining component of $C^{R}=C^{U}$ corresponds to 


$$
\begin{aligned}
\widehat{C}_{2}^{U} & =C^{U}-\widehat{C}_{1}^{U} \\
& =\int_{p} x_{2}\left(p_{1}, p_{2}, q^{1}, u^{0}\right) d t-\int_{p} x_{2}\left(p_{1}, p_{2}, q^{0}, u^{0}\right) d t .
\end{aligned}
$$

Again, without strong structural assumptions regarding the nature of preferences, the analyst is unlikely to have an estimate of the functional form for $x_{2}$, which in turn precludes the computation of $\widehat{C}_{2}^{U}$, leaving the $\widehat{C}_{1}^{U}$ as that portion of $C^{R}$ that is recoverable.

\subsection{Environmental Quality as an Essential Good - A Household Production Story}

An alternative explanation for violations of weak complementarity arises from the household production approach to consumer behavior. ${ }^{15}$ In this case, individuals are assumed hold preferences over a bundle of commodities $\mathbf{z}=\left(z_{1}, \ldots, z_{M}\right)$. These commodities are in turn produced by combining the market commodities (x) and the public good $(q)$ through the household production process $t(\mathbf{z}, \mathbf{x}, q)=0$. If the production technology follows the simpler structure with $\mathbf{z}=\mathbf{z}(\mathbf{x}, q)$, then consumer preferences take the form:

$$
u=u[\mathbf{z}(\mathbf{x}, q)]
$$

As Freeman (1993, p. 149) notes, weak complementarity in this context corresponds to the assumption that $\mathbf{x}$ is an essential input to the production of the $z_{j}$ 's. However, this need not be the case. Indeed, if $\mathbf{x}$ is not an essential input and $q$ is, then weak complementarity does not hold and there is more to $C^{R}$ than the "use" value associate with the $x_{i}$ 's. Under this interpretation, there is an intrinsic value to the public good not captured by its association with the market. Thus, even when $x$ is not consumed, changes to the public good alter consumer welfare. ${ }^{16}$

What distinguishes this from the previous case is that there are no omitted variables or other mis-specifications in the empirical model. Thus, the model the analyst is estimating is in fact the true model. Consequently, the welfare measure $C^{R}$ derived from equation (6) is fully revealable in this case.

We complete this section by noting one additional explanation for violations of weak 
complementarity. The previous two explanations have taken the "high road", using theory and modeling issues to explain the results. The "low road" of explanation may lie in the econometrics. ${ }^{17}$ As Randel (citation) has pointed out, prices in revealed preference models are likely measured with error, as are other variables entering the model that depend on an individual's recall while responding to a survey. Thus it may in fact be that weak complementarity holds, but we reject this in preference estimation due to data problems. Likewise, it may be that the utility function we estimate is incorrect or not sufficiently flexible and we reject weak complementarity although it would hold for the individual's true preference function. ${ }^{18}$ While these explanations may of course be true and undoubtedly contribute somewhat to deviations from weak complementarity, they could in fact be said about any empirical study. Thus the econometric issues may be orthogonal to the issues we examine here. As in any empirical study, one should seek to obtain the most reliable data and specify the most flexible model possible. Given this, the pragmatic issue of obtaining the proper welfare measures in any revealed preference model still remains. We examine this empirically using the KuhnTucker model in the following section

\section{EMPIRICAL INVESTIGATION}

We investigate these issues empirically using data obtained from the 1997 Iowa Wetlands survey conducted at Iowa State University. The purpose of this survey was to obtain information on Iowans' use of wetlands in the state as well as attitudes towards wetlands preservation and conservation. A survey of 6000 Iowa households was drawn from the general population and from state hunting and fishing license holders, from which 3131 useable surveys were returned. As part of the survey each individual was given a map of the state, divided into fifteen zones, and asked to record the number of visits to wetlands made to each of the zones during 1997.

Of particular interest for this example are the responses of individuals living in the northcentral part of the state encompassing three of the zones. This area is known as the Des Moines lobe of the North American prairie pothole region. The prairie pothole region is a large, fairly 
unique section of the continent, including parts of Iowa, Minnesota, the Dakotas, and the Canadian plains provinces. The area is dotted with indentations (formed by retreating glaciers) in otherwise flat landscapes, which are wet for at least part of the year. This type of wetland is ideal habitat for many types of wildlife including ducks and pheasants, and is important at both the local and continental level. At the local level, these wetlands and the surrounding upland areas provide opportunities for outdoor recreation, including hunting, hiking, and wildlife viewing. In this application we model visits to the three prairie pothole zones by individuals living in the region. This sub-sample includes 296 respondents, of whom 191 visited a wetland in the region during 1997. Of these individuals, only eleven visited wetlands in each of the three zones comprising the prairie pothole region. A model is therefore necessary which can account for nonparticipation and corner solutions in the data, and allow specification of preferences that are sufficiently general to allow both use and non-use components to resource values.

The Kuhn-Tucker model is attractive for this purpose. The model begins with maximization of the consumer's direct utility function subject to income and non-negativity constraints. The first order conditions, given the potential for non-consumption of a subset of the goods, take the form of the Kuhn-Tucker conditions. Formally the consumer solves the problem

$$
\underset{\mathbf{x}, z}{\operatorname{Max}} u(\mathbf{x}, z, q, \boldsymbol{\gamma}, \boldsymbol{\varepsilon})
$$

s.t.

$$
\mathbf{p}^{\prime} \mathbf{x}+z \leq y
$$

and

$$
z \geq 0, x_{j} \geq 0, j=1, \ldots, M
$$

where $u(\cdot)$ is assumed to be a quasi-concave, increasing, and continuously differentiable function of $(\mathbf{x}, z), \mathbf{x}=\left(x_{1}, \ldots, x_{M}\right)^{\prime}$ is a vector of goods to be analyzed (recreation trips), $\mathrm{z}$ is the numeraire good, $\mathbf{p}=\left(p_{1}, \ldots, p_{M}\right)^{\prime}$ is a vector of commodity prices (travel costs), $\mathrm{y}$ denotes annual income, 
$\gamma$ is a vector of parameters to be estimated, and $\varepsilon=\left(\varepsilon_{1}, \ldots, \varepsilon_{M}\right)^{\prime}$ is a vector of random disturbances capturing the variation in preferences in the population. Note that a priori, the specification of utility need not in general exhibit the property of weak.

Assuming the numeraire good is necessary, the first order conditions for this problem are given by

$$
u_{j} \leq p_{j} u_{z} ; x_{j} \geq 0 ; x_{j}\left[u_{j}-p_{j} u_{z}\right]=0, j=1, \ldots, M
$$

Given assumptions on the structure of the utility function, the KT conditions can be rewritten as

$$
\varepsilon_{j} \leq g_{j}(\mathbf{x}, y, \mathbf{q}, \gamma) ; \quad x_{j} \geq 0 ; x_{j}\left[\varepsilon_{j}-g_{j}(\mathbf{x}, y, \mathbf{q}, \gamma)\right]=0, \quad j=1, \ldots, M,
$$

where $g_{j}(\cdot)$ is a function of observed variables and parameters to be estimated, determined by the choice of functional form for utility. Equation (37) provides the basis for forming estimating equations for the model. Given a distribution for the error terms, the probability of observing each individual's outcome in the data can be determined from (37) and maximum likelihood used to recover estimates of the parameters. ${ }^{19}$

Because of the non-negativity constraints, the demand system, and hence the indirect utility function of interest for welfare analysis, is non-differentiable. For example, if there are $M$ sites available, there are $2^{M}$ different combinations of sites that can be visited, including the possibility of not visiting any of the sites during the season. Therefore there is an equal number of potential demand systems, conditional on the demand regime. Let

$$
\Omega=\{\varnothing,\{1\},\{2\}, \ldots,\{M\},\{1,2\}, \ldots,\{1, M\}, \ldots,\{1,2, \ldots M\}\}
$$

denote the collection of all possible demand patterns and $v\left(\mathbf{p}_{\omega}, q, y, \gamma, \varepsilon\right)$ denote the indirect utility function when the individual is restricted to the commodities indexed by $\omega \in \Omega$. Note the maximization process implies the conditional indirect utility function is a function of only the prices of consumed goods, while the absence of weak complementarity implies the conditional 
indirect utility function may in fact be a function of all quality attributes, regardless if they are consumed. The individual's unconditional indirect utility function is then given by

$$
v(\mathbf{p}, q, y, \gamma, \varepsilon)=\max _{\omega \in \Omega}\left\{v_{\omega}\left(\mathbf{p}_{\omega}, q, y, \gamma, \varepsilon\right)\right\}
$$

Note that this corresponds to the indirect utility function, $v(\mathbf{p}, q, y)$, which is in fact the separable component of the overall utility function given in (2). As noted above, revealed preference methods can at best expose information on resource values given by $C^{R}$. In the particular case of the KT model, this is implicitly defined by

$$
\max _{\omega \in \Omega^{0}}\left\{v_{\omega}\left(\mathbf{p}_{\omega}, q^{0}, y, \gamma, \varepsilon\right)\right\}=\max _{\omega \in \Omega^{1}}\left\{v_{\omega}\left(\mathbf{p}_{\omega}, q^{1}, y-C^{R}, \gamma, \varepsilon\right)\right\}
$$

and may, if preferences are not weakly complementary, include indirect use value. Direct use value, or $C^{U}$ as defined in equation (13), is given by by $C^{U}=C^{R}-C^{I U}$, where $C^{I U}$ is implicitly defined by

$$
\max _{\omega \in \Omega^{0}}\left\{v_{\omega}\left(\tilde{\mathbf{p}}_{\omega}, q^{0}, y, \gamma, \varepsilon\right)\right\}=\max _{\omega \in \Omega^{1}}\left\{v_{\omega}\left(\tilde{\mathbf{p}}_{\omega}, q^{1}, y-C^{I U}, \gamma, \varepsilon\right)\right\}
$$

where $\tilde{\mathbf{p}}_{\omega}$ is the vector of choke prices for each of the demand regimes. Note that the preferences in (33) are characterized via estimation up to an unobserved vector of error terms, and that no closed form for the compensating surpluses given by equations (40) and (41) exist. Given an estimated distribution for the error term, however, Monte Carlo integration can be used to obtain estimates of the expected value of the surplus measures. ${ }^{20}$

Estimation of the KT model requires specification of the functional form for the utility function and the error terms. We assume utility is given by a version of the LES utility function such that

$$
U(\mathbf{x}, z ; \mathbf{q}, \gamma, \varepsilon)=\sum_{j=1}^{M} \Psi_{j}\left(q_{j}, \varepsilon_{j}\right) \ln \left(x_{j}+\theta_{j}\right)+\ln (z)
$$

where $\gamma=(\delta, \theta), \Psi_{j}$ is a quality index give by $\Psi_{j}\left(q_{j}, \varepsilon_{j}\right)=\exp \left(\delta_{0}+\delta_{1} p h_{j}+\varepsilon_{j}\right)$, and $p h_{j}$ is a site quality variable equal to the pheasant count in the $j^{\text {th }}$ site if the individual indicated 
possession of a hunting or fishing license and equal to zero otherwise. The price of visiting each of the sites is computed in the standard manner, using the round trip travel distance and one third of the marginal wage rate as the opportunity cost of travel time. While restrictive in some ways the LES utility function is convenient for this study in that it does not a priori impose weak complementarity on preferences. Note that if $\theta_{j}=1,\left.\left(\partial U / \partial \Psi_{j}\right)\right|_{x_{j}=0}=0$ and preferences are weakly complementary while if $\theta_{j}>1$ preferences conversely do not exhibit weak complementarity. Thus, for this specific specification of utility, estimation of $\theta$ provides a parametric test for weak complementarity. To foreshadow what is to come, rejection of weak complementarity requires the analyst to make decisions on the proper welfare measure, based on which explanation for non-weakly complementary preferences is most plausible.

It is further assumed that the random terms are distributed independent, identical extreme value. While more general distributions are possible (see Phaneuf, et. al), this specification provides a closed form for the likelihood function and allows direct re-sampling from the estimated error distribution, significantly simplifying the estimation and welfare calculation process. ${ }^{21}$ Given these assumptions, we estimate the three-site KT model using the prairie pothole sub-sample from the Iowa Wetlands data. For comparison purposes, we also estimate a standard four-good repeated multinomial logit model. ${ }^{22}$ The results of estimation are presented in Table 1.

We estimate two specifications of the KT model, an unrestricted and a restricted version. The unrestricted model freely estimates $\theta_{j}$ for each site while the restricted model restricts each of these parameters to equal to one, imposing weak complementarity on the preference structure. Both models are parsimonious in parameters, and in each case all estimates are significantly different from zero at better than the $1 \%$ confidence level. As expected, increases in pheasant counts at each site will increase utility and positively affect the demand for trips. These parameters characterize preferences, which can then be used to calculate elasticities and other measures of policy interest. 
Of particular interest for the topic of this paper are the estimates of $\theta_{j}$. Note that in each case the estimates are significantly different from one at any reasonable confidence level, and that the restricted model is rejected against the unrestricted model in a likelihood ratio test at the $1 \%$ significance level. Thus, for this specification of utility in this application, weak complementarity is rejected. Welfare calculations corresponding to equation (40) above will contain not only pure use value, but also indirect use. The analyst must thus determine which is the correct measure to report. For this example, we consider the effects of a $20 \%$ increase in pheasant counts throughout the prairie pothole region and calculate three KT welfare measures, along with the comparable repeated multinomial logit welfare measure. Each of these could be considered correct under various assumptions.

If we adopt the interpretation of the omitted variables story---that weak complementarity is rejected because the model does not explicitly model the demand for goods which are also in the weakly complementary set of goods--- then it will be most correct to calculate and report $C^{U}$. The degree to which our estimate of $C^{U}$ is biased will depend, as indicated earlier, on the degree of correlation between the prices, the functional form of demand, and the magnitude of the cross price effect. Although the magnitude of the bias is clearly an empirical question that will vary across applications, we suspect that in most cases it will be small to not be a significant cause of concern. Thus, the omitted variables interpretation would suggest that the analyst report a use value of about $\$ 88$ per season for a $20 \%$ increase in the pheasant population. It is useful to once again note that this value does not consider the change in values of the weakly complementary goods which are not included in the model.

In contrast, if we believe the model is correctly specified and the rejection of weak complementarity is evidence of the essential nature of $q$, then it would seem most correct to calculate and report the full value of $C^{R}$, including both the pure use value and the residual indirect use value. Thus, the analyst would report that a $20 \%$ increase in the pheasant population 
would yield about $\$ 322$ of surplus. The analyst might further break this value down into the two components of use (about \$88) and non-use (about \$234), but it is not clear that there is any intrinsic value to doing the latter.

In either of the previous two cases, it will be important for the analyst to clearly identify which welfare measure has been calculated and reported. It is apparent from the large differences in the magnitudes of the welfare measures that this decision has potentially large implications for the outcome of benefit cost comparisons and other uses of welfare numbers.

Finally, for comparison we also present welfare calculation arising from the restricted KT model and the repeated logit model. Interestingly, the welfare result from the logit model of $\$ 36$ for $C^{R}=C^{U}$ is of a comparable order of magnitude to the use value from the unrestricted $\mathrm{KT}$ model. In contrast, the use value obtained from the ex ante restricted KT model is the implausibly high $\$ 778$. This provides some antidotal support for estimating unrestricted preferences in KT models, rather than ex ante imposing weak complementarity.

\section{FINAL REMARKS}

In this paper, we investigate the implications of non weakly complementary preferences for applied welfare analysis using revealed preference data. Although existence value can not be measured using RP data, there is a component of total value outside of standard use value (deemed "indirect use" value here) for which revealed preference approaches may be able to shed some light. The purpose of this paper is to highlight this issue and begin to investigate its implications for welfare measurement. Our motivation is pragmatic, in that the recently available KT model does not a priori impose weak complementarity, requiring the analyst to determine which is the correct welfare measure to report. Critical to understanding welfare measurement when weak complementarity does not hold is to first understand and define the relevant components of total value. We do so with a particular focus on identifying the components of total value that are recoverable, at least potentially, from revealed preference data and models. 
We propose two explanations for why weak complementarity may be violated in any particular empirical setting, and mention a third: weak complementarity with sets of goods, a household production model with quality is an essential input, and econometric explanations. We note that the implications for welfare analysis are quite different in each of the cases, and that the proper welfare measure will depend on the judgement of the analyst. Those inherently uneasy about anything beyond direct use value in revealed preference models will likely be most comfortable with the first interpretation and the associated welfare measures.

The Kuhn-Tucker model is a convenient framework for investigating these issues empirically as weak complementarity does not have to be imposed ex ante, but rather can be tested for in the context of the model. An application of this model to wetlands usage in the prairie pothole region of the state of Iowa suggests that weak complementarity does not hold between visits to wetlands and pheasant populations. Further, the two interpretations of why weak complementarity does not hold yield welfare magnitudes of sufficient difference to warrant further investigation into these issues. Steps in this direction may include estimating KT models using more general functional forms for utility and/or the error distribution. 
Table 1: Estimation and Welfare Results

\begin{tabular}{|c|c|c|c|c|}
\hline \multirow[b]{2}{*}{ Parameters } & \multicolumn{4}{|c|}{ Model } \\
\hline & Unre & cted & Restricted & Logit \\
\hline$\theta_{1}$ & \multicolumn{2}{|c|}{$\begin{array}{c}7.15 \\
(0.83)\end{array}$} & NA & NA \\
\hline$\theta_{2}$ & \multicolumn{2}{|c|}{$\begin{array}{c}6.72 \\
(0.79)\end{array}$} & NA & NA \\
\hline$\theta_{3}$ & \multicolumn{2}{|c|}{$\begin{array}{c}8.44 \\
(1.00)\end{array}$} & NA & NA \\
\hline$\delta_{0}$ & \multicolumn{2}{|c|}{$\begin{array}{l}-5.78 \\
(0.16)\end{array}$} & $\begin{array}{l}-8.91 \\
(0.25)\end{array}$ & NA \\
\hline$\delta_{1}$ & \multicolumn{2}{|c|}{$\begin{array}{c}0.0103 \\
(0.0021)\end{array}$} & $\begin{array}{c}0.024 \\
(0.0049)\end{array}$ & NA \\
\hline$v$ & \multicolumn{2}{|c|}{$\begin{array}{l}0.5839 \\
(0.033)\end{array}$} & $\begin{array}{c}1.36 \\
(0.074)\end{array}$ & NA \\
\hline$\beta_{0}$ & \multicolumn{2}{|c|}{ NA } & NA & $\begin{array}{c}1.69 \\
(0.07)\end{array}$ \\
\hline$\beta_{y}$ & \multicolumn{2}{|c|}{ NA } & NA & $\begin{array}{c}0.05 \\
(0.001)\end{array}$ \\
\hline$\beta_{p}$ & \multicolumn{2}{|c|}{ NA } & NA & $\begin{array}{c}0.023 \\
(0.001)\end{array}$ \\
\hline Log-likelihood & \multicolumn{2}{|c|}{-1241} & -1354 & -7202 \\
\hline Welfare Scenario & $C^{R}$ & $C^{U}$ & $C^{R}$ & $C^{R}$ \\
\hline $\begin{array}{l}20 \% \text { increase in pheasant } \\
\text { counts at all site }\end{array}$ & $\begin{array}{c}\$ 322 \\
(83)\end{array}$ & $\begin{array}{l}\$ 88 \\
(33)\end{array}$ & $\begin{array}{l}\$ 778 \\
(166)\end{array}$ & $\begin{array}{l}\$ 36 \\
(11)\end{array}$ \\
\hline
\end{tabular}

Note: Standard errors on welfare measures computed via 200 bootstrap replications. 


\section{APPENDIX}

The purpose of this appendix is to demonstrate that the welfare decomposition in equation (5) and originally proposed by Hanemann (1988) holds only if the marginal utility of

income is constant. To see this, note that, from equation (6), $C^{R}$ can be equivalently defined as implicitly solving the equality

$$
v\left(\mathbf{p}^{0}, q^{0}, y\right)=v\left(\mathbf{p}^{0}, q^{1}, y-C^{R}\right) .
$$

However, equations (4) and (7) imply that:

$$
\begin{aligned}
T\left[v\left(\mathbf{p}^{0}, q^{0}, \tilde{y}\right), q^{1}\right] & =T\left[v\left(\mathbf{p}^{0}, q^{1}, y-C^{T}\right), q^{1}\right] \\
& =T\left[v\left(\mathbf{p}^{0}, q^{1}, \tilde{y}-C^{R}\right), q^{1}\right],
\end{aligned}
$$

where $\tilde{y} \equiv y-\tilde{C}$. This in turn implies that

$$
v\left(\mathbf{p}^{0}, q^{0}, \tilde{y}\right)=v\left(\mathbf{p}^{0}, q^{1}, \tilde{y}-C^{R}\right) .
$$

Clearly, equations (43) and (45) will generally hold only if the marginal utility of income is constant. 


\section{REFERENCES}

1. Becker, G. S., "A Theory of the Allocation of Time," Economic Journal, 75(1965): 493-517.

2. Bockstael, N. E. and C.L. Kling, "Valuing Environmental Quality: Weak Complementarity with Sets of Goods," American Journal of Agricultural Economics 70(1988): 654-662.

3. Bockstael, N. E. and K.E. McConnell, "Welfare Measurement in the Household Production Framework," American Economic Review 73(1983): 806-814.

4. Bockstael, N. E. and K.E. McConnell, "Public Goods as Characteristics of Non-market Commodities," Economics Journal 103(1993): 1244-1257.

5. Carson, R. T., N. E. Flores, and R. C. Mitchell, "The Theory and Measurement of PassiveUse Value,” in Bateman, I. J. and K. G. Willis (eds.), Valuing Environmental Preferences: Theory and Practice of the Contingent Valuation Method in the U.S., E.U., and Developing Countries, Oxford University Press: Oxford, 1999.

6. Freeman, A.M., The Measurement of Environmental and Resource Values: Theory and Methods, Resources for the Future: Washington, D.C., 1993.

7. Hanemann, W.M. "Three Approaches to Defining 'Existence' or 'Non-use' Value under Certainty," unpublished paper,University of California, Berkeley, July 1988.

8. LaFrance, J., "Incomplete Demand Systems, Weak Separability, and Weak Complementarity,” Tucson: University of Arizona, Department of Agricultural and Resource Economics, Working Paper \#77, December 1992.

9. Lancaster, K. J., “A New Approach to Consumer Theory,” Journal of Political Economy, 74(1966): 132-57.

10. Madariaga, B. and K.E. McConnell. "Exploring Existence Value," Water Resources Research 23(1987): 936-42.

11. Mäler, K.G., Environmental Economics: A Theoretical Inquiry, Baltimore MD: Johns Hopkins University Press for Resources for the Future, 1974. 
12. McConnell, K. E., "Existence and Bequest Value," in R. D. Rowe and L. G. Chestnut (eds.) Managing Air Quality and Scenic Resources at National Parks and Wilderness Areas, Westview Press: Boulder, CO, 1983.

13. Phaneuf, D.J. and J.A. Herriges, "Choice Set Definition in a Kuhn-Tucker Model of Recreation Demand", forthcoming in Marine Resources Economics.

14. Phaneuf, D.J., C.L. Kling, and J.A. Herriges, "Estimation and Welfare Calculations in a Generalized Corner Solution Model with an Application to Recreation Demand," Review of Economics and Statistics (2000): forthcoming.

15. Wales, T.J., and A. D. Woodland, "Estimation of Consumer Demand Systems with Binding Nonnegativity Constraints," Journal of Econometrics, 21(1983): 263-285. 


\section{FOOTNOTES}

${ }^{1}$ This is a generalization of Freeman's (1993, pp. 123-24) "hopeless" case in which he assumes that $q$ enters only as strongly separable component of utility.

${ }^{2}$ It is assumed that $T(u, q)$ is strictly increasing in $u$.

${ }^{3}$ A proof of this is provided in the Appendix.

${ }^{4}$ Obviously, one could reverse the order of compensation by defining $\tilde{C}^{R}$ such that:

$$
T\left[v\left(\mathbf{p}^{0}, q^{0}, \tilde{y}\right), q^{1}\right]=T\left[v\left(\mathbf{p}^{0}, q^{1}, \tilde{y}-\tilde{C}^{R}\right), q^{1}\right],
$$

where $\tilde{y} \equiv y-\tilde{C}$. In this case, the decomposition would be $C^{T}=\tilde{C}^{R}+\tilde{C}$ and the counterpart to equation (10) would become

$$
\begin{aligned}
T\left[v\left(\mathbf{p}^{0}, q^{0}, y\right), q^{0}\right] & =T\left[v\left(\mathbf{p}^{0}, q^{0}, y-\tilde{C}\right), q^{1}\right] \\
& =T\left[v\left(\mathbf{p}^{0}, q^{1}, y-\tilde{C}-\tilde{C}^{R}\right), q^{1}\right] .
\end{aligned}
$$

There are two reasons to prefer the decomposition in (8). First, from a practical point view, since the functional form for $T(\cdot, q)$ can never be identified from revealed preference data, $\tilde{C}$ cannot be computed and, consequently, neither can $\tilde{y}$ or $\tilde{C}^{R}$. Second, even if $\tilde{C}$ was known, as long as $q$ is a normal good $C^{R}>\tilde{C}^{R}$, so that $C^{R}$ represents the largest portion of total value that can be extracted from behavioral data.

${ }^{5}$ The compensation $C^{E}$ is similar to Carson, Flores, and Mitchell's (1999) notion of "passive-use" value; i.e., “...those portions of total value ... that are unobtainable using indirect measurement techniques which rely on observed market behavior."(p. 100). We have chosen not to use the term "passive-use" value, however, to avoid confusion with notion of indirect use (e.g., reading magazines, etc., concerning a recreation site) that is included in $C^{R}$.

${ }^{6}$ See LaFrance (1992) for additional discussion regarding testing of the weak complementarity restriction. 
${ }^{7}$ In Freeman's terms $C^{I U}$ could also be referred to as "non-use" value. We avoid this terminology here to prevent confusion, since in other works "non-use" value and "existence" value have been used synonymously. As previously noted, in this case $C^{E}$ amd $C^{I U}$ have quite different interpretations. ${ }^{8}$ In fact, as Hanemann (1988, p. 1) notes, decompositions analogous to (13) and (14) are valid for any intermediate prices, although the terminologies of use or non-use values would be less intuitive.

${ }^{9}$ For the time being, we ignore the problem of income effects in the demand equations.

${ }^{10}$ See, e.g., Phaneuf, Kling, and Herriges (2000).

${ }^{11}$ See, e.g., Bockstael and McConnell (1983) or Freeman (1993).

${ }^{12}$ The expression in (17) represents one way to write the compensating (or equivalent) variation, based on the path of integration $\left(p_{1}^{0}, p_{2}^{0}\right) \rightarrow\left(\tilde{p}_{1}(q), p_{2}^{0}\right) \rightarrow\left(\tilde{p}_{1}(q), \tilde{p}_{2}(q)\right)$. Of course, the same welfare compensation would result if the alternative path $\left(p_{1}^{0}, p_{2}^{0}\right) \rightarrow\left(p_{1}^{0}, \tilde{p}_{2}(q)\right) \rightarrow\left(\tilde{p}_{1}(q), \tilde{p}_{2}(q)\right)$ had been used, yielding $C^{T}=\tilde{C}_{1}^{U}+C_{2}^{U}$. More generally, the welfare measure can be expressed as a line integral that is path independent for the Hicksian welfare measures. See Bockstael and Kling (1988) for the derivation and discussion.

${ }^{13}$ For the linear model in (21), it can be shown that bias $_{1}$ is in fact zero on average if: (1) the initial price for good 1 (i.e., $\left.p_{1}^{0}\right)$ is the same across all households, (2) the initial price of good $2\left(p_{2}^{0}\right)$ is symmetrically distributed about the population mean $\left(\bar{p}_{2}^{0}\right)$, and (3) all households are users (i.e., $x_{1}>0$ ) prior to (after) a quality increase (decrease). If condition (3) is violated, bias $_{1}$ will on average be negative (positive) for a quality increase (decrease).

${ }^{14}$ Ideally, the analyst know that the second good exists and be able to realistically impose sufficient structure on preferences to allow all of parameters of the expenditure function to be recovered through the estimated demand function for good 1 (e.g., in an LES system). The resulting bias $_{R}$ would then be limited if $p_{2}^{0}$ varied little, if at all, in the population.

${ }^{15}$ See, for example, Becker (1965), Lancaster (1966), and Bockstael and McConnell (1983). 
${ }^{16}$ While difficult to quantify, one can tell stories consistent with these types of preferences. For example, if an individual is unable to go fishing with his friends because of other commitments but later enjoys hearing stories about how great the fishing was, he is producing utility from the environmental good without consuming the complement. Thus, weak complementarity does not hold in the structure of the individual's preferences for the single good.

${ }^{17}$ Thanks to Ted McConnell for suggesting these descriptive titles.

${ }^{18}$ For example, Phaneuf, Kling, and Herriges (2000) reject the weak complementarity restriction using a linear expenditure system utility function. It may in fact be that this function for preferences is not sufficiently flexible and that the test is rejecting the LES model and not weak complementarity per se. This is, of course, a possibility and further research is need into the use of flexible functional forms in KuhnTucker framework. However, as the LES form is a legitimate preference structure, the question remains as to what one would do if LES preferences apply and violations of weak complementarity arise.

${ }^{19}$ See Phaneuf, Kling, and Herriges (2000) or Phaneuf and Herriges (2000) for further details on implementing the KT model.

${ }^{20}$ See Phaneuf, Kling, and Herriges for a discussion of the necessary algorithm for computing welfare measures in the Kuhn-Tucker model. This process, while computationally intense, is conceptually simple once the conditional indirect utility functions are recovered.

${ }^{21}$ Additional details on estimation and welfare calculation can be found in Phaneuf, et.al or Phaneuf and Herriges. Example GAUSS programs for estimation and welfare measures for the LES/EV model are available from the authors upon request.

${ }^{22}$ The repeated multinomial logit model conditional indirect utility functions are given by $V_{j}=\beta_{y}\left(y-p_{j}\right)+\beta_{p} p h_{j}+\varepsilon_{j}, j=1, \ldots, 3$, and $V_{0}=\beta_{0}+\beta_{y} y+\varepsilon_{0}$ for the option of not making a trip. Fifty choice occasions were used and income $(y)$ was calculated as annual income divided by the number of choice occasion. 